\title{
Liang Lemdubu: A Pleistocene Cave Site in the Aru Islands
}

\author{
Sue $0^{\prime}$ Connor ${ }^{1}$, Ken Aplin², Katherine Szabó ${ }^{1}$, Juliette Pasveer ${ }^{1}$, Peter Veth ${ }^{3}$, and Matthew Spriggs ${ }^{1}$ \\ 1. Department of Archaeology and Natural History, Research School of Pacific and Asian Studies, \\ The Australian National University, Canberra, ACT, Australia \\ 2. Sustainable Ecosystems, CSIR0, GPO Box 284, Canberra, ACT 2601, Australia \\ 3. Research Unit, Australian Institute of Aboriginal and Torres Strait Islander Studies, Canberra, ACT, Australia
}

\section{Introduction}

Liang Lemdubu is located in the western interior of Pulau Kobroor in an area of karstic limestone (Fig. 9.1). This large, doubleentranced cave was formed when an ancient subterranean river cut a passage through the limestone. It runs in length for $30 \mathrm{~m}$, is up to eight metres wide and has an average height of three metres (Figs 9.2, 9.3). To reach it one has to boat to the upper reaches of Sungai Papakulah, followed by a two hour walk inland through rainforest. This is the same sungai where Alfred Russell Wallace spent six weeks collecting skins and other specimens in 1857, at the hamlet he called 'Wanumbai'.

Lemdubu is regarded locally as a sacred cave and despite its relative inaccessibility, it is known outside of the Wanumbai area. We first heard of it from people at the village of Ujir whilst surveying the northwest coast during our 1995 field season. Excavation did not begin until the following field season in 1996, after consultation had been carried out with the owner of the land and the adat (customary law) leader for the cave, a resident of

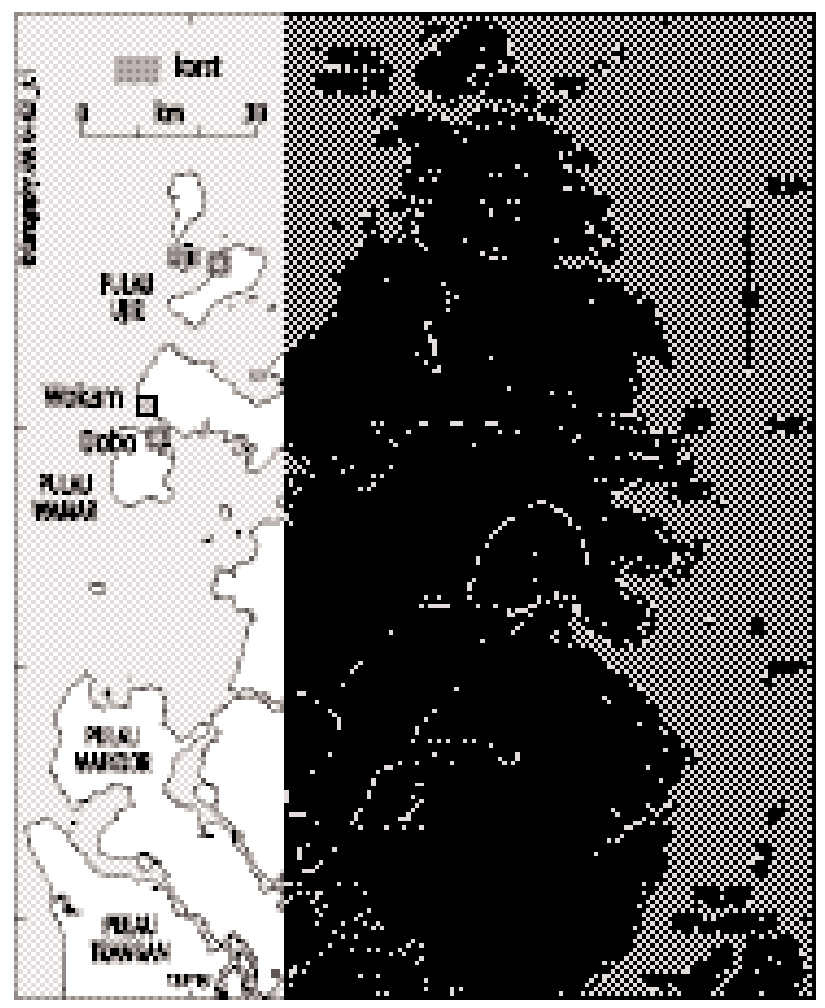

Figure 9.1 Liang Lemdubu: map showing location of the cave and the area of karst limestone in which the cave is located Papakulah Besar. 


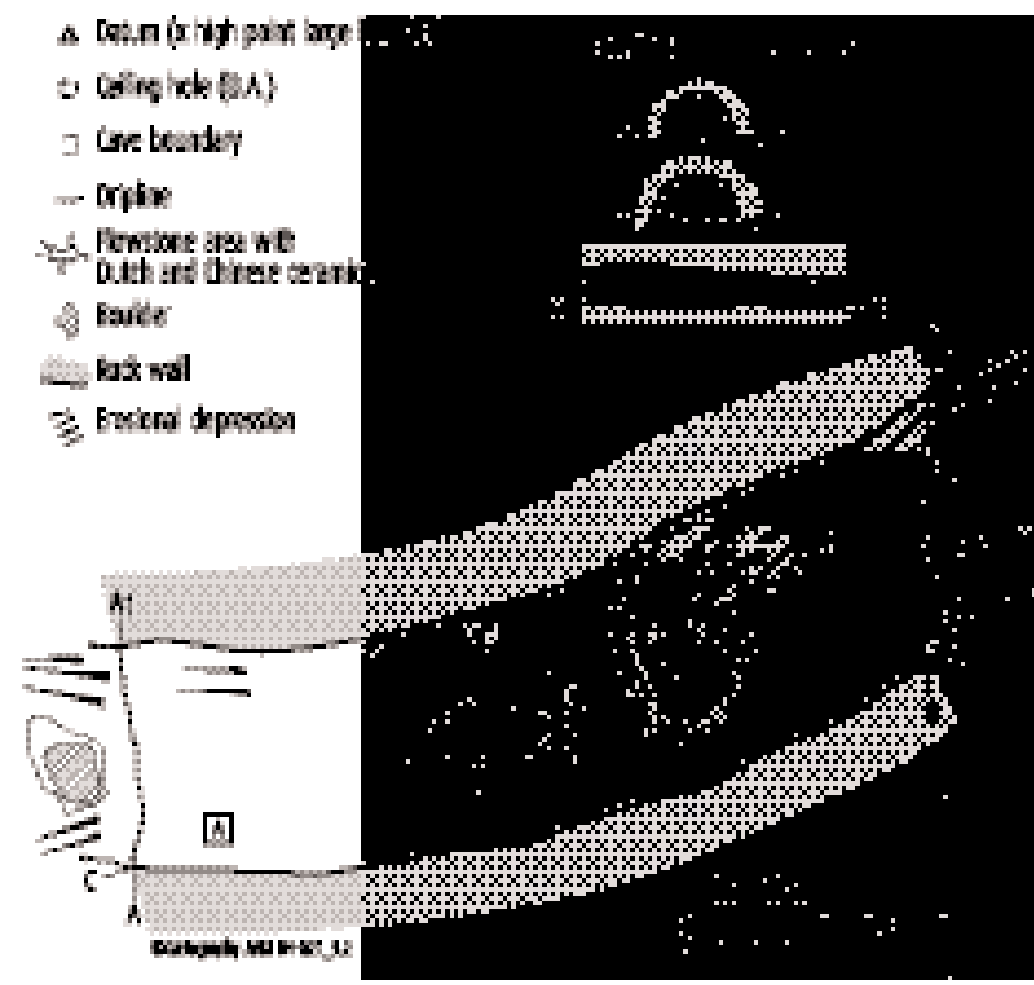

Figure 9.2 Liang Lemdubu: plan of the cave showing location of features discussed in the text and locations of Test Pits $A$ and $C$

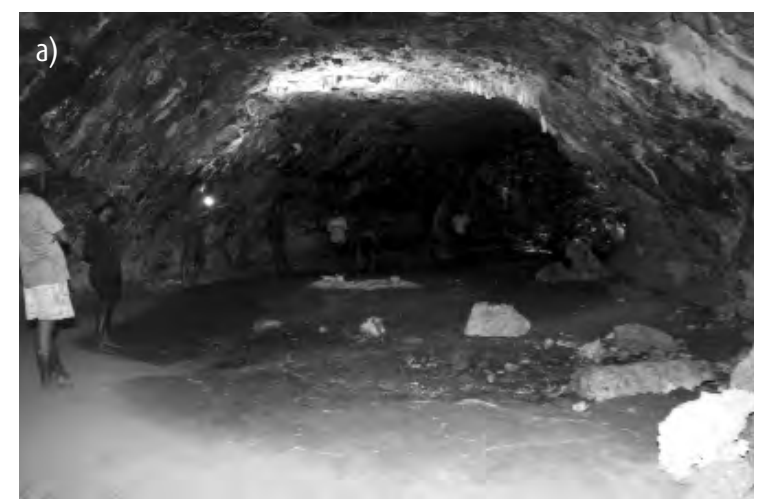

Figure 9.3a Liang Lemdubu: view to west inside the cave with natural flowstone platform with ceramics at mid-centre

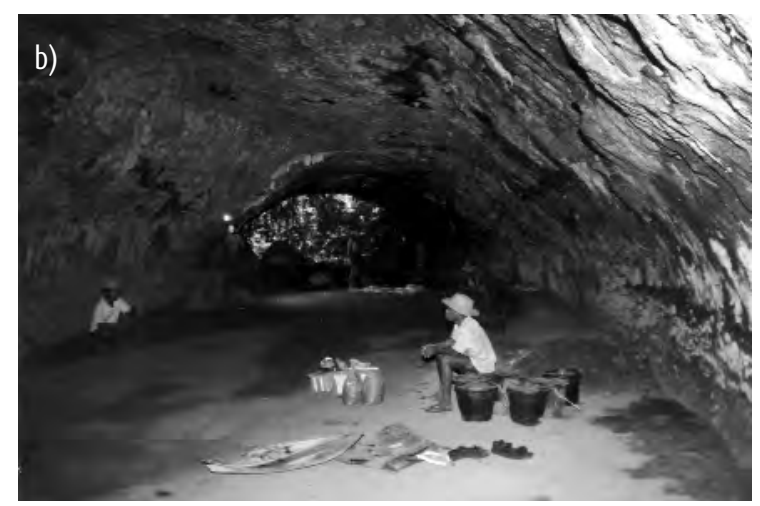

Figure 9.3b Liang Lemdubu: view to east entrance
Small stalactite formations occur in the central third of the cave, beneath which a platform of flowstone has accumulated (Fig. 9.3a). The water which drips through the roof at this point is believed to have sacred properties and to imbue the drinker with strength, health and long life; we were told that the cave was still visited periodically to collect the water in times of crisis or ill health. In historic times, Dutch and Chinese ceramics were placed on the flowstone platform and these are now cemented to it (Fig. 9.3a). There is a small hole in the roof in this area through which water and limited sediments enter the cave; this minor collapse appears quite recent.

Lemdubu lies about $25 \mathrm{~m}$ above sea level and represents a high point in the low-lying local landscape. While other caves were located during our field survey in the surrounding karstic formations, most were low-lying, wet, and unsuitable for human habitation. Lemdubu was the only cave of its size and elevation located during three field seasons, which no doubt accounts for its notoriety.

The cave is surrounded by evergreen rainforest which has a fairly simple structure (Monk et al. 1997:198, 203). Immediately around the cave the rainforest is uncleared but within a few hundred metres to the east it is interrupted by sago swamps and small mixed garden clearings, planted to meet subsistence requirements (Fig. 9.4). At the time of our last visit in 1997 the area was being more intensively cleared for cash crop coffee plantings.

The densest concentrations of cultural material on the extensive sediment floor of Lemdubu are located in the better lit areas at the east and west entrances, near the driplines. Shellfish (Geloina sp. and Terebralia sp.), pottery and animal bone were noted on the surface, along with pieces of matting and bamboo indicating the contemporary use of the cave by 


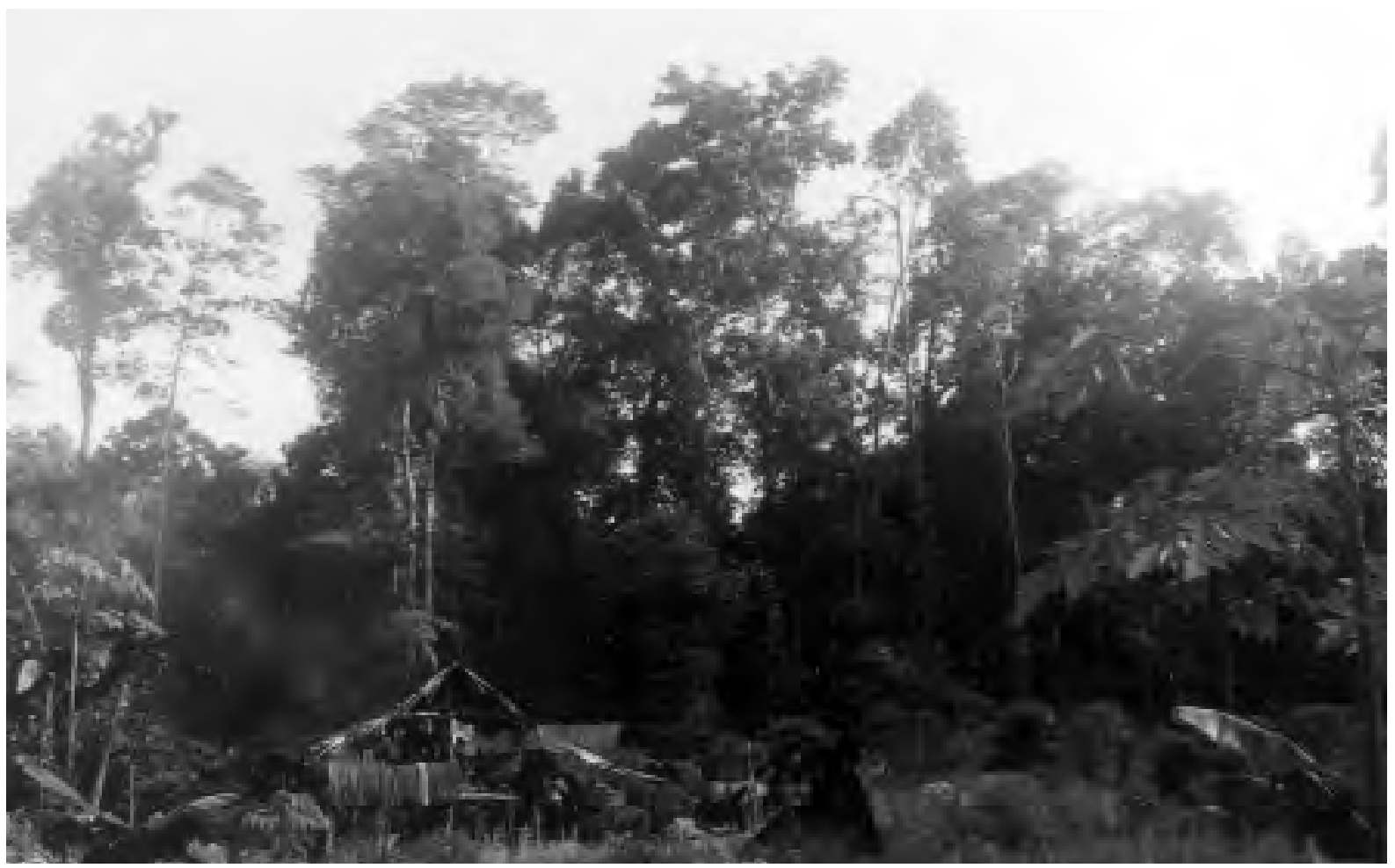

Figure 9.4 Liang Lemdubu: cleared garden area where our base camp was located, approximately $1.5 \mathrm{~km}$ from the cave

villagers while on hunting trips or to collect the sacred water. Our initial judgment was that the deposits immediately inside the dripline at each end of the cave were likely to be the deepest and the least disturbed by water action, roots, and major roof fall events. These areas were also more likely to have been the focus of daily occupation than the darker interior of the cave.

\section{The Excavations and Stratigraphy}

Two test pits (A and C) were excavated at either end of the cave (Fig. 9.2). Excavation units (spits) averaged approximately five centimetres unless sediment changes were apparent, in which case depths varied to accommodate changes in the stratigraphy. All material was wet sieved through fine mesh $(<2 \mathrm{~mm})$. Volumes of excavated sediment were recorded prior to wet sieving and an initial sort of cultural residues was carried out at the cave to remove large non-cultural limestone fragments. The remaining material from each excavated unit or 'spit' was then bagged for secondary sorting back at base camp where it was rewashed, thoroughly dried and re-sorted. We found that this method led to the recovery of even small pieces of micro-debitage and bone.

Prior to excavation, it was agreed that the excavated material from Lemdubu would be divided between ourselves and our Indonesian co-workers. All the material and records from Test Pit A were deposited in Puslit Arkenas in Jakarta; to our knowledge, these have not yet been analyzed. The cultural material from Test Pit $\mathrm{C}$ was returned to Canberra for analysis. It is this material that forms the basis of this report.

Initially a $1 \times 1 \mathrm{~m}$ pit, Test Pit A, was dug at the western end of the cave (Fig. 9.2). This pit revealed a homogeneous, loose grey-brown to yellowish brown sediment, which changed to a dark yellowish brown mottled clay immediately above the sterile, basal deposit. The upper spits of the grey-brown sediment contained charcoal, terrestrial fauna, earthenware pottery, marine shellfish, stone artefacts, and a fragment of metal. Deeper spits lacked shellfish and pottery and produced fewer stone artefacts, but yielded abundant terrestrial fauna. The basal mottled clay was 


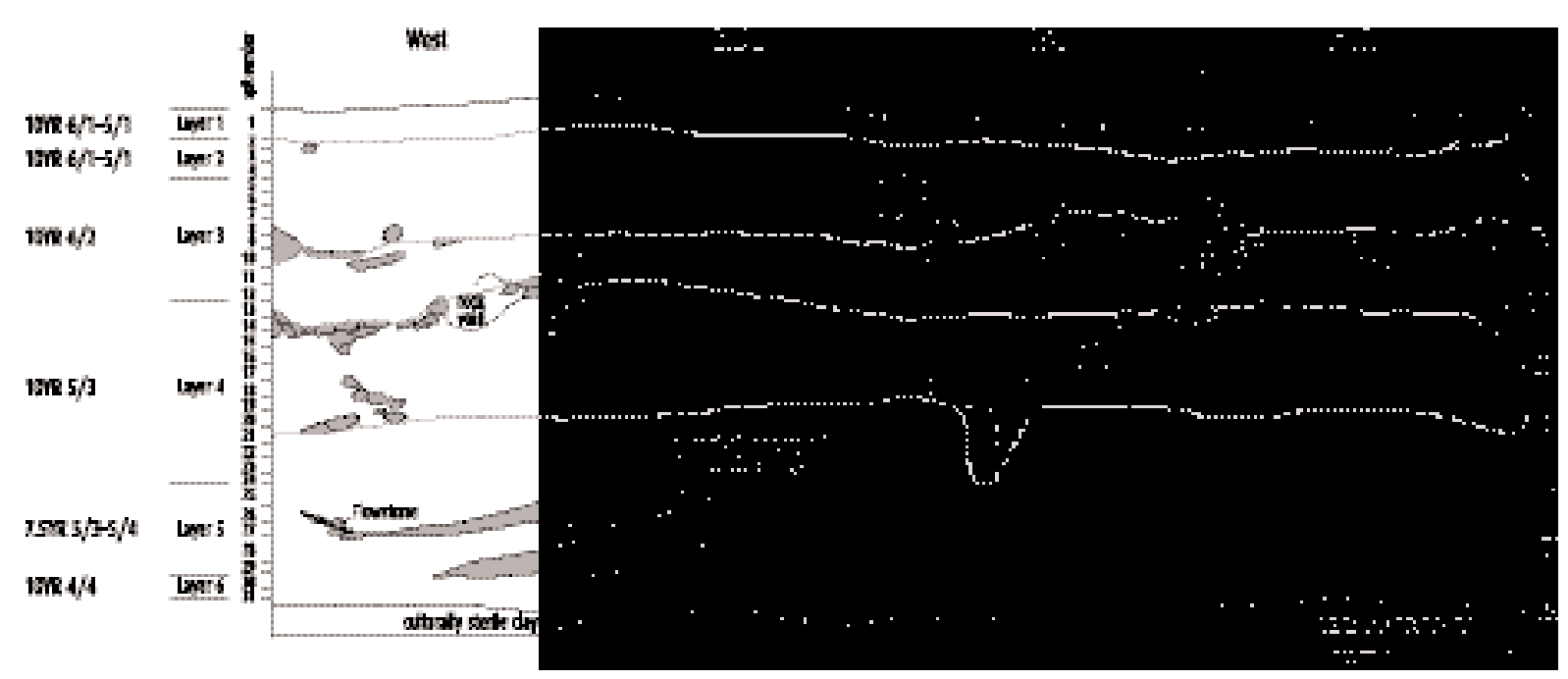

Figure 9.5 Liang Lemdubu: sections of Test Pit C showing spit depths

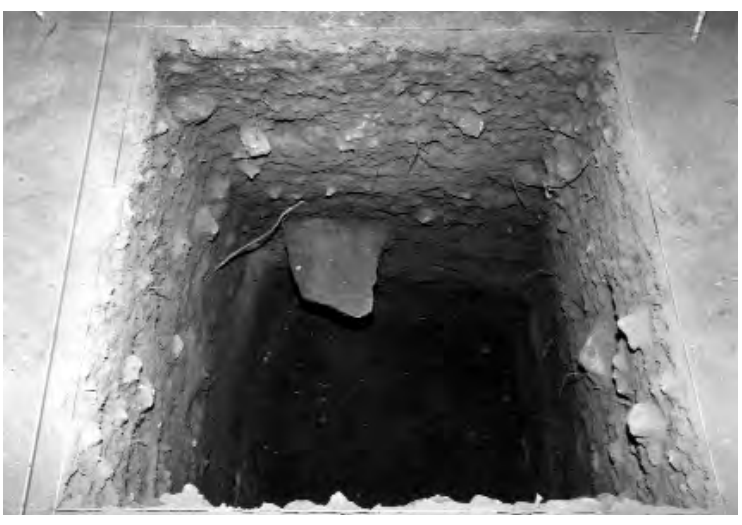

Figure 9.6 Liang Lemdubu: east section of Test Pit C, showing stone placed over burial

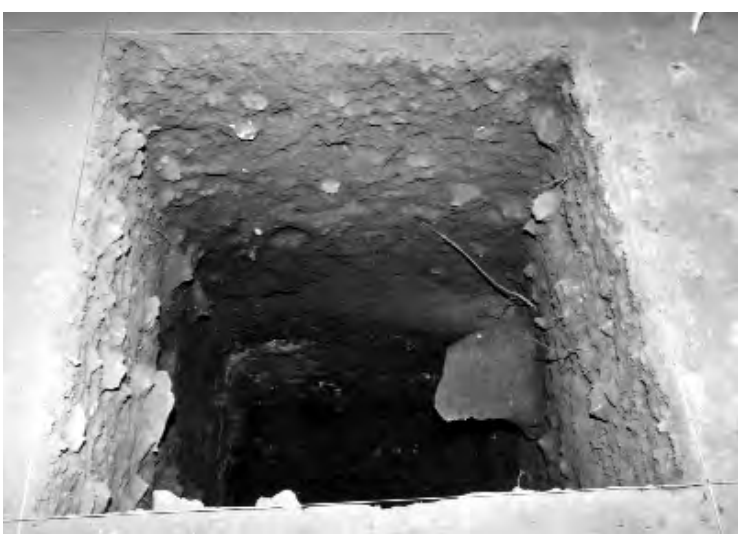

Figure 9.7 Liang Lemdubu: north section of Test Pit C, showing flowstone near base of pit reached at approximately $50 \mathrm{~cm}$ below the surface in Test Pit A. This yielded a small quantity of bone but otherwise appeared culturally sterile.

Test Pit C was located near a massive boulder at the eastern end of the shelter (Figs 9.2, 9.3b). This $1 \times 1 \mathrm{~m}$ pit revealed a similar but extended sequence to Test Pit A (Fig. 9.2). Six layers were recognised on the basis of variation in the sediment and cultural materials down the profile. These included: sediment colour; the degree of consolidation of the deposit; differences in texture and/or changes in clay and sand content, and quantities or size of clastic material; as well as changes in the cultural materials, such as presence or absence of shell and degree of cementation of bone. Bulk samples were collected from most spits during excavation of Test Pit $\mathrm{C}$ and averaged approximately $200 \mathrm{~g}$. Larger samples were not practical for transportation from the field. The sequence described below is based on an examination of the bulk samples and on information recorded on the excavation field sheets. The layers do not always have a one to one correspondence with the divisions as drawn on the sections at completion of the excavation. Figure 9.5 shows Layers 1-6 as well as the unmodified section drawing as it was reproduced in $\mathrm{O}^{\prime}$ Connor et al. (2002). The sediments from the bulk samples are logged in Appendix 9.1. As would be anticipated in a limestone cave, the sediments were alkaline throughout the sequence $(\mathrm{pH}$ 8.0-9.0), and bone and shell were well preserved throughout. 
Culturally sterile deposits were reached at approximately $150 \mathrm{~cm}$ below the surface and excavation was discontinued without reaching bedrock at approximately $160 \mathrm{~cm}$ (Figs 9.5-9.7).

Layer 1 comprises the top spit only: Spit 1 . This layer is composed of a grey to greyish brown sediment (Munsell hue 10YR 6/1-5/1). The deposit was unconsolidated and contained large lumps of charcoal. This layer is differentiated from Layer 2 primarily because it was loose and powdery, probably as a result of ongoing disturbance of the surface.

Layer 2 includes Spits 2 through to the base of Spit 4. It is essentially the same as Layer 1 (Munsell 10YR 6/1-5/1), but has been consolidated following burial. It has slightly more fine silts than Layer 1, and the sands are well sorted. It contains less charcoal and the charcoal pieces are much smaller in size.

Layer 3 was recognized as beginning at Spit 5 and continuing down to the base of Spit 12. Although the sediment colour was close in hue to Layer 2 (Munsell 10YR 6/2), this layer was differentiated because it contained significantly less shellfish than the layers above, no visible charcoal, and significantly more bone and small clasts. A particular concentration of rounded, cobble-sized limestone clasts was observed in Spits 8, 9 and 10. The appearance of bone breccia in Spit 10 indicates a zone of carbonate mobilization and it is possible that some clasts are carbonate nodules formed in situ as a result of water percolation through the profile. Alternatively, the clasts may represent degraded pieces of roof fall. The field notes indicate that many of the cobbles in Spit 12 were particularly chalky 'as if weathered'. It is possible that they represent a roof fall event following which they lay exposed for some time prior to being covered by sediment.

Layer 4 comprises Spits 13 to 24. It was recognized on the basis of a slight change in sediment colour (Munsell 10YR 5/3) and texture. The sediment is recorded as moister, 'stickier' and slightly lighter or more orange in colour, with a major increase in clay content. The finds from the spits in this layer had to be wet sieved twice as so much fine clay adhered to them. A major decrease in roof fall or nodules was noted as occurring in Spit 21. The human burial occurred in this level under the large rock in Spits 17 and 18.

Layer 5 comprises Spits 25 to 29, and was recognized on the basis of a slight change in sediment colour (Munsell 7.5YR 5/3-5/4) and texture. The sediment becomes much stickier with coarser gritty inclusions. In the northern and northwestern area of the square, two travertine flowstone floors were recorded in Spits 25, 26, and 28 (Fig. 9.7). These formed a partial seal over the underlying deposit which in places was over five centimetres thick and had to be broken up with a crowbar.

Layer 6 begins at approximately $150 \mathrm{~cm}$ below the surface and comprises Spits 30 and 31. The sediments in this layer are more yellowish in hue (Munsell 10YR 4/4) than those in Layer 5, and have an even higher clay content. This layer contained small bones but no definite cultural material. The fauna in Layer 6 is presumed to predate the first human occupation of the site. Excavation was discontinued in this layer at a maximum depth of $160 \mathrm{~cm}$, as the sediments were deemed to be culturally sterile.

\section{Dating the Lemdubu Sequence}

Little charcoal was preserved below the upper three spits and we have therefore dated a variety of different materials, using a range of techniques, in an attempt to obtain a chronology for the cave sequence (Table 9.1). Radiocarbon age estimates were obtained on charcoal, marine shellfish, Celtis seeds, Casuarius eggshell, and a human tooth. All radiocarbon values were calibrated using CALIB 3.4. No ocean reservoir correction has been applied to the marine samples as no standards are available for this equatorial region. ESR was used to estimate the antiquity of the human burial distributed between Spits 18 to 23, and Uranium-Thorium dates were obtained on the travertine 
TABLE 9.1 LIANG LEMDUBU: TEST PIT C, RADIOMETRIC DATES a, b

\begin{tabular}{|c|c|c|c|c|c|c|}
\hline Lab. code & Spit & Depth (cm) & Sample type & $\delta^{13} \mathrm{C}$ & $\begin{array}{l}\text { Conventional age } \\
\text { (YEARS BP, } \pm 1 \sigma)\end{array}$ & $\begin{array}{l}\text { Calibrated age } \\
\text { (CAL YEARS BP) }\end{array}$ \\
\hline ANU-10782 & 2 & $5-10$ & Charcoal & -24.0 & $1830 \pm 60$ & $1574-1916$ \\
\hline OZF247 & 2 & $5-10$ & Casuarius eggshell & -13.5 & $2150 \pm 50$ & $2000-2308$ \\
\hline ANU-10794 & 3 & $10-15$ & Charcoal & -24.0 & $1100 \pm 160$ & $708-1295$ \\
\hline ANU-10792 & 5 & $25-30$ & Geloina shell & -10.7 & $11,700 \pm 130$ & $13,183-14,057$ \\
\hline OZF356 & 5 & $20-25$ & Celtis seed & -16.2 & $9400 \pm 50$ & $10,432-11,055$ \\
\hline 0ZF358 & 7 & $30-35$ & Celtis seed & -12.4 & $9280 \pm 50$ & $10,242-10,635$ \\
\hline $0 Z 0701$ & 8 & $35-40$ & Celtis seed & -16.9 & $8170 \pm 60$ & $9006-9397$ \\
\hline OZF357 & 10 & $45-50$ & Celtis seed & -15.3 & $9250 \pm 60$ & $10,242-10,577$ \\
\hline $0 Z D 460$ & 17 & $85-90$ & Geloina shell & -5.8 & $16,570 \pm 510$ & $18,391-21,019$ \\
\hline$A A-32848$ & 19 & $95-100$ & Casuarius eggshell & -10.0 & $16,770 \pm 110$ & $19,321-20,658$ \\
\hline 0ZF248 & 19 & $95-100$ & Casuarius eggshell & -11.7 & $16,850 \pm 120$ & $19,402-20,760$ \\
\hline $0 Z C 776$ & 19 & $95-100$ & Geloina shell & -5.0 & $17,750 \pm 450$ & $19,835-22,287$ \\
\hline $0 Z C 777$ & 26 & $130-135$ & Charcoal & $-24.0 d$ & $13,300 \pm 300$ & $14,539-16,794$ \\
\hline- & 26 & $130-135$ & Flowstone & & & $25,700 \pm 460$ \\
\hline- & 28 & $140-145$ & Flowstone & & & $27,020 \pm 290$ \\
\hline \multicolumn{7}{|c|}{$\begin{array}{l}\text { a In addition to the dates reported here an ESR date of } 18,800 \pm 2300 \text { years (linear uptake model) was obtained on a tooth representing human remains distribute } \\
\text { across excavation layers, Spits } 18-23\end{array}$} \\
\hline \multicolumn{7}{|c|}{ b All analyses are radiocarbon dates with the exception of two flowstone U-series dates at the base of the sequence } \\
\hline \multicolumn{7}{|c|}{ c Minimum - maximum intercepts, $\pm 2 \sigma$ range } \\
\hline \multicolumn{7}{|c|}{ d This sample was too small to measure the delta $13 \mathrm{C}$} \\
\hline
\end{tabular}

flowstones in Spits 26 and 28. The dates on the human burial are not included in Table 9.1 as they are bone dates and therefore date the burial itself and not the age of the sediments that it was interred within.

Charcoal from Spit 2 returned an age-estimate of 1830 60 (ANU-10782), and from Spit 3 an estimate of $1100 \pm 160$ (ANU-10794). Thus there is a minor inversion in the charcoal age estimates between Spit 2 and 3. An AMS radiocarbon determination was also obtained on Casuarius eggshell

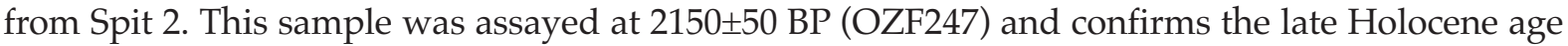
of Spit 2.

We conclude that the upper three spits are Late Holocene in age. The age estimates are consistent with the recovery of pottery and domestic animal remains only from these spits (Table 9.2). Insufficient charcoal was available below Spit 3 for conventional radiocarbon determinations, and small-sized charcoal samples were avoided due to a high risk of vertical displacement within the deposit and of contamination during the process of excavation. Spit 4 remains undated, but as it contains large quantities of shellfish and minimal quantities of Agile wallaby bone (a species that became locally extinct in the early Holocene; see Chapter 7, this volume, and below), we infer that it is likely to also be Late Holocene in age.

Although marine/estuarine molluscs are abundant only in Spits 1-4, they are present in smaller quantities in Spits 5 and 6 (Table 9.2). It was therefore anticipated that Spit 5 would date to the period of sea level stabilization approximately 6000 years ago. However, a single Geloina coaxans valve (ANU-10792) from Spit 5 returned an age estimate of 11,700 \pm 130 BP, considerably older than predicted. A sample of Celtis seed from Spit 5 was also analyzed and returned an age estimate of $9400 \pm 50$ BP (OZF356). The two dates for Spit 5 indicate that at least some of the cultural material in this unit was deposited during the terminal Pleistocene or earliest Holocene. Two Celtis samples from Spits 7 and 10 (OZF358 and OZF357, respectively) yielded similar age estimates to OZF356 from Spit 5. A fourth Celtis sample from Spit 8 (OZD701) gave a slightly younger estimate. If the Celtis dates provide a generally accurate indication of age, Spits 5-10 accumulated fairly rapidly in the terminal Pleistocene/ early Holocene, between 9000 and 11,000 cal BP. 
Table 9.2 Liang Lemdubu: Test Pit C, weights ( $\mathrm{g}$ ) of cultural material by spit (this table supersedes an earlier version published in $0^{\prime}$ Connor et al. 2002)

\begin{tabular}{|c|c|c|c|c|c|c|c|}
\hline CONV. AGE BP & SPIT & $\begin{array}{c}\text { STONE } \\
\text { ARTEFACTS }\end{array}$ & BONE & $\begin{array}{c}\text { MARINE/ } \\
\text { ESTUARINE SHELL }\end{array}$ & $\begin{array}{l}\text { CELTIS } \\
\text { SEEDS }\end{array}$ & CHARCOAL & $\begin{array}{c}\text { CASSOWARY } \\
\text { EGGSHELL }\end{array}$ \\
\hline & 1 & 54.1 & 1178.7 & 2227.9 & 11.3 & 57.6 & 4.4 \\
\hline $1830 \pm 60$ & 2 & 11.4 & 430.5 & 515.1 & 7.6 & 5.5 & 2.3 \\
\hline \multirow[t]{2}{*}{$1100 \pm 60$} & 3 & 22.0 & 361.0 & 526.2 & 5.3 & 0.8 & 0.2 \\
\hline & 4 & 2.8 & 475.0 & 286.0 & 4.6 & 0.2 & 2.6 \\
\hline \multirow[t]{2}{*}{$9400 \pm 50$} & 5 & 5.9 & 617.4 & 52.6 & 3.9 & & 0.3 \\
\hline & 6 & 5.7 & 546.1 & 23.7 & 1.1 & 0.2 & \\
\hline \multirow[t]{3}{*}{$9280 \pm 50$} & 7 & 167.6 & 1085.2 & 2.2 & 0.8 & & \\
\hline & 8 & 89.2 & 1162.9 & 0.2 & 0.1 & & \\
\hline & 9 & 54.6 & 2062.1 & 2.7 & 0.2 & 0.8 & \\
\hline \multirow[t]{7}{*}{$9250 \pm 60$} & 10 & 216.7 & 3482.7 & 4.1 & 0.1 & 0.01 & \\
\hline & 11 & 10.6 & 1352.6 & 2.0 & 0.1 & & \\
\hline & 12 & 53.7 & 1241.7 & 0.1 & & & \\
\hline & 13 & 4.5 & 1168.8 & 2.4 & & & \\
\hline & 14 & 26.3 & 1591.8 & 1.2 & & & \\
\hline & 15 & 32.7 & 1488.2 & 0.1 & & & \\
\hline & 16 & 3.2 & 1658.4 & 1.7 & & & \\
\hline \multirow[t]{2}{*}{$16,570 \pm 510$} & 17 & 7.9 & 1566.3 & 9.5 & & & 0.1 \\
\hline & 18 & 1.9 & 1421.3 & 1.5 & & & 0.1 \\
\hline \multirow[t]{7}{*}{$16,850 \pm 120$} & 19 & 6.3 & 2112.9 & 7.2 & & & 1.7 \\
\hline & 20 & 0.5 & 2400.6 & & & & 0.2 \\
\hline & 21 & & 2433.8 & & & & \\
\hline & 22 & & 1567.6 & & & & \\
\hline & 23 & 0.2 & 1531.9 & & & & \\
\hline & 24 & 2.6 & 3356.4 & & & & \\
\hline & 25 & 1.7 & 5665.8 & & & & \\
\hline \multirow[t]{2}{*}{$25,700 \pm 460$} & 26 & & 1912.0 & & & & \\
\hline & 27 & & 1004.2 & & & & \\
\hline \multirow[t]{4}{*}{$27,020 \pm 290$} & 28 & & 640.9 & & & & \\
\hline & 29 & 0.1 & 207.9 & & & & \\
\hline & 30 & & 91.7 & & & & \\
\hline & 31 & & 59.3 & & & & \\
\hline
\end{tabular}

The Geloina fragment from Spit 17 (OZD460) returned an estimated age of 16,570 5520 BP. This value is broadly consistent with the results of two radiocarbon determinations on Casuarius

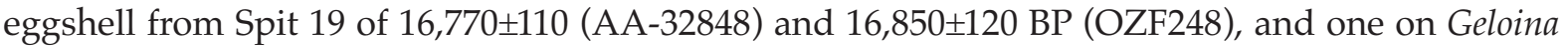
shell from Spit 19 of 17,750 4450 BP (OZC776). The two Casuarius eggshell dates are statistically identical and although the A/I ratios for these samples are slightly different $-0.407 \pm 0.001$ (AAL 8559C) and $0.390 \pm 0.005$ (AAL 8559C) - the possibility must be considered that they derive from the same egg but have had slightly different thermal histories (see Chapter 13, this volume). However, even if the Casuarius eggshell samples (AA-32848 and OZF248) are not independent ages, the production of close age estimates on the two valves of Geloina from Spits 17 and 19 with the Casuarius from Spit 19 provides reason for confidence in the inference that Spits 17-19 accumulated between 18,400 and 22,200 cal BP.

As mentioned above, small-sized charcoal samples were not used for radiocarbon analyses as their provenance was uncertain. The exception to this was a small fleck of dark coloured material, tentatively identified as charcoal, which was found adhering to the flowstone from Spit 26. As this part of the sequence clearly had not been disturbed during the period after travertine deposition, and furthermore, the flowstone fragment had not been through the wet sieving 
process, there seemed little possibility of modern or ancient contamination. However, the sample yielded an anomalously young age estimate of 13,300 $\pm 300 \mathrm{BP}$ (OZC777), which is at odds with the suite of mutually supportive age estimates from Spits 17-19, and with age estimates obtained from Uranium-Thorium analysis of other pieces of flowstone from the same level (see below). In view of these radically different chronological estimates, we are now inclined to think that the sample was not charcoal but rather some kind of secondary carbonaceous deposit.

Attempts were made to directly date a human burial which occurs predominantly between Spits 18 and 23, using AMS radiocarbon dating of bone collagen and ESR dating of tooth enamel. The stratigraphic position of the burial is shown in Figures 9.5 and 9.6, and the morphological description and analyses are presented fully in Bulbeck (Chapter 12, this volume). The results of the analyses and dating of the burial are reported in some detail here as they are critical to the reliability of the assessment of the Lemdubu burial's age.

Three independent radiocarbon analyses aimed at extracting collagen from the bone produced inconsistent results. Two laboratories were unable to extract any datable material from the bone, while a third laboratory, the Australian Nuclear Science and Technology Organisation (ANSTO), produced a late Holocene determination. A section was cut from the medial diaphysis fragment of the right femur (from Spit 18) for the purpose of getting an AMS radiometric analysis of the bone from ANSTO. This section of femoral bone was divided and the other half sent to Donald Pate's laboratory at Flinder's University, in an attempt to get a stable isotope ratio assay. The section sent to ANSTO (OZD577) was assayed at 3180 BP. However, the reliability of the ANSTO analysis on OZD577 must be evaluated in the light of the failure by Pate to extract any collagen from the bone. This raised the prospect that the ANSTO analysis was not carried out on collagen extant in the bone sample, but rather on some contaminant. A third sample of the same section of femoral bone was then submitted to the AMS dating facilities at Oxford as a further check on the ANSTO determination. The Oxford laboratory was also unable to extract datable material from the bone. On this basis alone - that the extraction of datable material could not be replicated by two high quality laboratories - we conclude that the ANSTO analysis must be regarded as an unreliable estimate of the age of the burial. Furthermore, the ANSTO radiocarbon determination is inconsistent with the stratigraphic context of the burial in relation to all other age estimates presented here, and with the ESR analysis obtained for the tooth from the burial, which was recovered from the same depth below surface in the excavation (Spit 18). When ANSTO was approached about the details of the collagen extraction for OZD577 their representative Ugo Zoppi (pers. comm.) stated that:

OZD577 was first pretreated in October $1998 \ldots$ the high $\mathrm{C} / \mathrm{N}$ ratio and low value of $\mathrm{d}^{13} \mathrm{C}$ (-26 per mil) for the second attempt at extracting collagen indicated that the extracted collagen still consisted of some humic acid contamination and was not suitable for dating. As a result the age estimate of $3180 \mathrm{BP}$ should be used as a minimum age.

Taking all of these lines of evidence together, OZD577 is regarded as unreliable and is not used in subsequent discussion of the chronology of Lemdubu burial.

The tooth used in the ESR analysis, also from Spit 18, is thought to belong to the same individual as the femur described above. The analyses and dating were undertaken by Rainer Grün at the Australian National University. The ESR analysis was carried out using a single aliquot technique (for experimental details see Grün 1995; for details on ESR age estimation see Grün 1989). The tooth yielded an age estimate of $15,800 \pm 1800$ years if a model of early Uranium-uptake is employed, and an age of $18,800 \pm 2300$ years if a model of linear Uranium-uptake is used. The sample has surprisingly high uranium concentrations. In view of the young age of the sample, it is unlikely that the early uptake model (which assumes that the uranium that is measured migrated into the sample in a very short time compared to its age) is applicable. Grün therefore considers an 
ESR age of $18,800 \pm 2300$ years to be the best estimate for the human burial (Grün pers. comm., September 2001). This implies that the human remains are roughly contemporaneous with the deposition of Spit 17 or 18, and were not dug into the deposit from much higher in the profile. The ESR date accords well with the stratigraphic context of the burial which shows a large stone in Spits 17 and 18 capping the burial (Fig. 9.6), and no evidence of vertical displacement of cultural materials found in the Holocene levels into the Pleistocene levels of the deposit.

Uranium-Thorium $(\mathrm{Th} / \mathrm{U})$ age estimates were obtained for fragments of speleothems found in Spits 26 and 28. One flowstone formed a partial seal over the deposit beginning at $130 \mathrm{~cm}$ below the surface in Spits 25 and 26, and a lower flowstone occurred at approximately $150 \mathrm{~cm}$ below the surface, mostly in Spit 28 (Fig. 9.7). Analytical methods follow that of Ayliffe et al. (1998), and the results are reported in full by O'Connor et al. (2002). The Th/U ages indicate that the lower portion of the cultural deposit, represented by material in Spits 26-28, is approximately 25-28,000 years old.

\section{The Liang Lemdubu Cultural Sequence}

Several features of the assemblage were evident during excavation and the on-site sorting of material. The estuarine molluscs found on the surface were restricted to the upper few spits. These levels also produced occasional pottery sherds along with the remains of introduced species such as pig and dog. Other vertebrate faunal remains in these levels were noticeably burnt and fragmented. At greater depth, the vertebrate remains became more abundant and less fragmented, with remains of small to medium-sized wallabies particularly evident. Stone artefacts were present in fairly low numbers throughout the sequence. Most were small and not typologically distinctive. The abundant faunal remains held promise of a detailed record of environmental change and human exploitation of game around the site.

Raw weights for all cultural material are presented in Table 9.2, and weights adjusted for difference in volume of sediment removed in each excavation unit are presented in Table 9.3. The depth of spits as they correspond with the volume of sediment removed can be found in Appendix 9.2. Some shell and bone is cemented with calcium carbonate and sediment, and this will tend to inflate the weights slightly in most levels. In Spits 25 and 26 this problem is exacerbated by the presence of several fragments of bone breccia cemented by travertine.

\section{Organic Remains}

\section{Molluscs}

\section{Marine/estuarine shellfish}

Marine/estuarine shellfish remains are relatively abundant in Spits 1-3. The quantity declines somewhat in Spit 4 and then falls dramatically below Spit 4 (at ca. $20 \mathrm{~cm}$ below surface level; Table 9.2, Fig. 9.8a). Occasional fragments of marine/ estuarine shell occur down to Spit 19.

Species represented include the gastropods Terebralia sp. and Ellobium aurismidae, which live intertidally amongst mangroves (Coleman 1981:19) and the bivalves Geloina coaxans, Anadara sp. and Isognomon sp. (see Table 9.4, Fig 9.8b). A few cowrie shells (Cypraeidae) were found in Spits 2 and 3. All shellfish found in the site, with the exception of the cowrie shells, probably could be obtained from the sungai, a few hours walk from the site.

Two morphologically similar bivalves, Geloina coaxans and Batissa violacea, are both represented in the samples. The primary way to distinguish between these bivalves is the nature of 
Table 9.3 Liang Lemdubu: Test Pit C, distribution and weights $(\mathrm{g})$ of cultural material through the sequence, adjusted for volume of deposit $\left(\mathrm{m}^{3}\right)$ removed per spit

\begin{tabular}{|c|c|c|c|c|c|c|c|c|}
\hline CONV. AGE BP & SPIT & $\begin{array}{c}\text { STONE } \\
\text { ARTEFACTS }\end{array}$ & BONE & $\begin{array}{c}\text { MARINE/ } \\
\text { ESTUARINE SHELL }\end{array}$ & $\begin{array}{l}\text { CELTIS } \\
\text { SEEDS }\end{array}$ & CHARCOAL & $\begin{array}{l}\text { CASSOWARY } \\
\text { EGGSHELL }\end{array}$ & $\begin{array}{c}\text { TOTAL } \\
\text { VOLUME }\end{array}$ \\
\hline & 1 & 54.1 & 1178.7 & 2227.9 & 11.3 & 57.6 & 4.4 & 5.0 \\
\hline $1830 \pm 60$ & 2 & 14.3 & 538.1 & 643.9 & 9.5 & 6.9 & 2.8 & 4.0 \\
\hline \multirow[t]{2}{*}{$1100 \pm 60$} & 3 & 36.7 & 601.7 & 877.0 & 8.8 & 1.3 & 0.3 & 3.0 \\
\hline & 4 & 4.7 & 791.7 & 476.7 & 7.6 & 0.3 & 4.4 & 3.0 \\
\hline \multirow[t]{2}{*}{$9400 \pm 50$} & 5 & 8.4 & 882.0 & 75.1 & 5.5 & & 0.5 & 3.5 \\
\hline & 6 & 9.5 & 910.2 & 39.5 & 1.8 & 0.3 & & 3.0 \\
\hline \multirow[t]{3}{*}{$9280 \pm 50$} & 7 & 239.4 & 1550.3 & 3.1 & 1.2 & & & 3.5 \\
\hline & 8 & 127.4 & 1661.3 & 0.3 & 0.1 & & & 3.5 \\
\hline & 9 & 68.3 & 2577.7 & 3.4 & 0.2 & 1.0 & & 4.0 \\
\hline \multirow[t]{7}{*}{$9250 \pm 60$} & 10 & 270.9 & 4353.4 & 5.1 & 0.1 & 0.01 & & 4.0 \\
\hline & 11 & 13.3 & 1690.8 & 2.5 & 0.1 & & & 4.0 \\
\hline & 12 & 89.5 & 2069.5 & 0.2 & & & & 3.0 \\
\hline & 13 & 7.5 & 1948.0 & 4.0 & & & & 3.0 \\
\hline & 14 & 37.6 & 2274.0 & 1.7 & & & & 3.5 \\
\hline & 15 & 54.5 & 2480.3 & 0.2 & & & & 3.0 \\
\hline & 16 & 5.3 & 2764.0 & 2.8 & & & & 3.0 \\
\hline \multirow[t]{2}{*}{$16,570 \pm 510$} & 17 & 13.2 & 2610.5 & 15.8 & & & 0.1 & 3.0 \\
\hline & 18 & 3.2 & 2368.8 & 2.5 & & & 0.1 & 3.0 \\
\hline \multirow[t]{7}{*}{$16,850 \pm 120$} & 19 & 10.5 & 3521.5 & 12.0 & & & 2.8 & 3.0 \\
\hline & 20 & 0.8 & 4001.0 & & & & 0.3 & 3.0 \\
\hline & 21 & & 2897.4 & & & & & 4.2 \\
\hline & 22 & & 2612.7 & & & & & 3.0 \\
\hline & 23 & 0.3 & 1914.9 & & & & & 4.0 \\
\hline & 24 & 3.3 & 4195.5 & & & & & 4.0 \\
\hline & 25 & 2.0 & 6745.0 & & & & & 4.2 \\
\hline \multirow[t]{2}{*}{$25,700 \pm 460$} & 26 & & 2390.0 & & & & & 4.0 \\
\hline & 27 & & 1434.6 & & & & & 3.5 \\
\hline \multirow[t]{4}{*}{$27,020 \pm 290$} & 28 & & 712.1 & & & & & 4.5 \\
\hline & 29 & 0.1 & 231.0 & & & & & 4.5 \\
\hline & 30 & & 114.6 & & & & & 4.0 \\
\hline & 31 & & 74.1 & & & & & 4.0 \\
\hline
\end{tabular}

the hinge; Batissa violacea has transversely serrated or grooved lateral teeth, whereas Geloina has smooth lateral teeth. Despite the broken and chalky condition of much of the shell, most of the hinge fragments examined were identified as Geloina coaxans. However, positive identifications of Batissa violacea were made in Spits 4, 6 and 10. The majority of the valve fragments are probably also from Geloina, nevertheless the possibility remains that some Batissa has been conflated with the Geloina.

Isognomon sp. is an oyster that lives on the roots of mangroves in estuarine environments. It has a very distinctive hinge and was easy to separate from the other bivalves. The bivalves Geloina and Isognomon sp., and the gastropods Terebralia sp. and Ellobium aurismidae, would probably have been available in the upper reaches of the Sungai Papakulah, which is the point at which the sungai is closest to the cave.

Live specimens of Geloina coaxans, Terebralia sp., and Ellobium aurismidae were collected in 1997 for comparison with those found in the deposit. The bivalve Batissa violacea is found in fresh to brackish water conditions and tolerates pools, creeks, and even fast flowing rivers. The upper reaches of the sungai are fed by freshwater streams coming off the higher limestone karst, and at 
Table 9.4 Liang Lemdubu: Test Pit C, marine and estuarine shellfish weights $(\mathrm{g})$ and minimum numbers of individuals (MNI) represented by spit

\begin{tabular}{|c|c|c|c|c|c|c|c|c|c|c|c|c|c|c|c|c|}
\hline SPIT & \multicolumn{2}{|c|}{$\begin{array}{l}\text { ANADARA SP. } \\
\text { (g) MNI }\end{array}$} & \multicolumn{2}{|c|}{$\begin{array}{l}\text { BATISSA } \\
\text { VIOLACEA } \\
\text { (g) } \mathrm{MNI}\end{array}$} & \multicolumn{2}{|c|}{$\begin{array}{l}\text { ISOGNOMON SP. } \\
\text { (g) MNI }\end{array}$} & \multicolumn{2}{|c|}{$\begin{array}{l}\text { GELOINA } \\
\text { COAXANS } \\
\text { (g) MNI }\end{array}$} & \multicolumn{2}{|c|}{$\begin{array}{c}\text { TEREBRALIA SP. } \\
\text { (g) MNI }\end{array}$} & \multicolumn{2}{|c|}{$\begin{array}{c}\text { ELLOBIUM SP. } \\
\text { (g) MNI }\end{array}$} & \multicolumn{2}{|c|}{$\begin{array}{l}\text { CYPRAEIDAE } \\
\text { (g) MNI }\end{array}$} & \multirow{2}{*}{$\begin{array}{c}\text { UNIDENTIFIED } \\
\text { SHELL } \\
(\mathrm{g}) \\
409.3\end{array}$} & \multirow{2}{*}{$\begin{array}{r}\text { TOTAL } \\
\text { SHELL } \\
(g) \\
2227.9\end{array}$} \\
\hline 1 & 17.6 & 1 & & & 3.4 & 2 & 1118.4 & 23 & 280.0 & 60 & 399.2 & 24 & & & & \\
\hline 2 & 31.6 & 2 & & & 8.9 & 2 & 167.4 & 6 & 98.6 & 19 & 128.8 & 7 & 0.7 & 1 & 79.1 & 515.1 \\
\hline 3 & 0.9 & 1 & & & 1.0 & 1 & 311.6 & 5 & 56.3 & 12 & 94.6 & 5 & 1.2 & 2 & 60.6 & 526.2 \\
\hline 4 & & & 16.0 & 2 & 0.7 & 1 & 200.7 & 10 & 1.0 & 1 & 10.0 & 1 & & & 57.6 & 286.0 \\
\hline 5 & 1.3 & 1 & & & & & 15.7 & 1 & 0.3 & 1 & 2.4 & 1 & & & 32.9 & 52.6 \\
\hline 6 & & & 5.0 & 1 & & & 6.8 & 1 & 0.3 & 1 & 0.8 & 1 & & & 10.8 & 23.7 \\
\hline 7 & & & & & & & 1.3 & 1 & 0.1 & 1 & & & & & 0.8 & 2.2 \\
\hline 8 & & & & & & & & & & & & & & & 0.2 & 0.2 \\
\hline 9 & & & & & & & 2.0 & 1 & 0.7 & 1 & & & & & & 2.7 \\
\hline 10 & & & 4.1 & 1 & & & & & & & & & & & & 4.1 \\
\hline 11 & & & & & & & 1.3 & 1 & & & & & & & 0.7 & 2.0 \\
\hline 12 & & & & & & & 0.1 & 1 & & & & & & & & 0.1 \\
\hline 13 & & & & & & & & & & & 2.4 & 1 & & & & 2.4 \\
\hline 14 & & & & & & & & & & & 1.2 & 1 & & & & 1.2 \\
\hline 15 & & & & & & & & & 0.1 & 1 & & & & & & 0.1 \\
\hline 16 & & & & & & & 1.7 & 1 & & & & & & & & 1.7 \\
\hline 17 & & & & & & & 9.5 & 1 & & & & & & & & 9.5 \\
\hline 18 & & & & & & & & & & & 1.5 & 1 & & & & 1.5 \\
\hline 19 & & & & & & & 7.2 & 1 & & & & & & & & 7.2 \\
\hline
\end{tabular}

a)
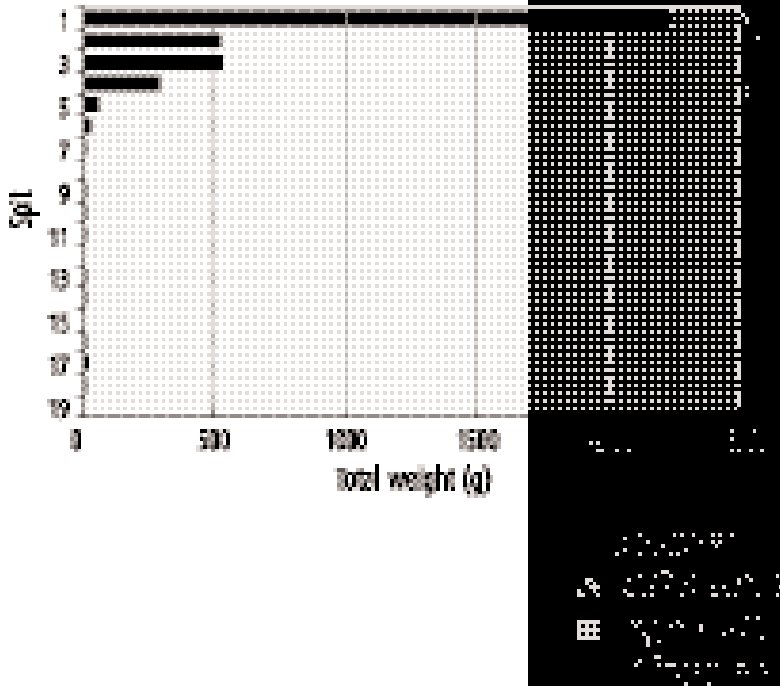

b)
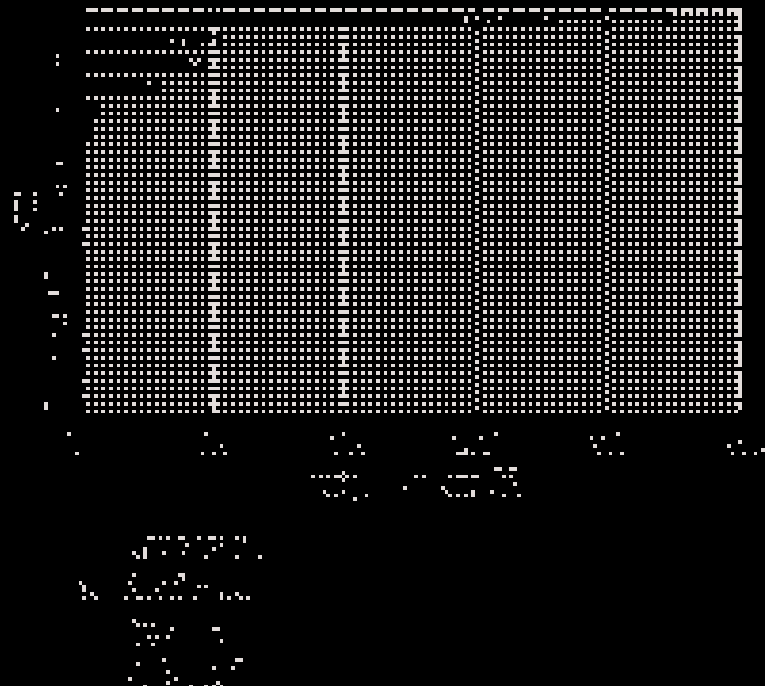

Figure 9.8 Liang Lemdubu: Test Pit $C$, a) shellfish raw weights $(g)$ per spit and b) weight $(g)$ by species per spit

low tide fresh to brackish water conditions prevail in some areas. Batissa violacea has been included with the estuarine molluscs as it may be obtainable in brackish pools at the head of the sungai, although none were observed in that habitat.

Small numbers of the marine/estuarine bivalve Anadara sp. - a group of species that inhabit sandy/muddy flats of the littoral zone - were recovered in the upper spits.

The few cowries must have been brought from a marine reefal environment and, in view of their small size, may have been transported inland as decorative items. However, none displayed any evidence of modification. Similarly, the Geloina fragments found in the lower spits may have 
been transported to the site for use as artefacts. Geloina with evidence of use wear and/or modification have been reported as artefacts from caves elsewhere in Island Southeast Asia. Their use as artefacts has also been confirmed in northern Australian sites where they occur at far greater distances inland (O'Connor 1999).

In terms of weight, the estuarine bivalve Geloina is clearly dominant within the shellfish assemblage (Fig. 9.8b). However, when measured by MNI, they are comparable to Ellobium but less numerous than Terebralia in the upper levels. Both measures of weight and MNI probably underrepresent the importance of Geloina relative to Terebralia and Ellobium, as the bivalves tend to fracture along the pallial line, and once broken the valves often split through the hinge and cannot be used for MNI. For this reason it is believed that the weights provide a more accurate estimate of the relative contribution of the different species. Most of the shell in the unidentified category is probably attributable to Geloina.

The decrease in shellfish remains with depth is not likely to be due to preservation. Although the shell does become less well preserved with depth, the species recorded in the upper four spits were easily identifiable from the more eroded fragments and identifiable fragments of Ellobium and Geloina were found down to Spits 18 and 19 respectively. Further, thin-shelled terrestrial snails increase in number at the same time as the marine species begin to decline; an unlikely scenario if preservation was influencing the survival of shell down the profile.

The vertical distribution of shellfish suggests that it is only in the upper three spits that conditions similar to those prevailing in Sungai Papakulah today were fully established. The mangrove-associated species Terebralia and Ellobium are only present in any numbers in the top three spits. Although Geloina occur in some numbers in Spit 4, this species is not strictly mangroveassociated and might be expected to appear prior to Terebralia and Ellobium. The small quantity of shell below Spit 5 would suggest that it was transported from some distance away.

\section{Terrestrial and freshwater gastropods}

The most numerically important of the terrestrial gastropods are Chloritis gruneri, Chloritis circumdata, Chloritis argillacea, Papuina sp. cf. P. pratti, Japonia sp. and Cyclotus politus. A number of so far unidentified species were recorded simply as species $\mathrm{A}-\mathrm{H}$. The freshwater gastropods Melanoides tuberculata, and Thiara scabra also make a minor contribution (Table 9.5). The distribution of terrestrial and freshwater gastropods through time is shown in Table 9.5 and Figure 9.9. All the species recorded are likely to be part of the extant fauna; however, there is no modern day list of species from the Aru Islands.

The freshwater snails are found on rocky substrate in variable conditions from stagnant pools to fast flowing rivers (Haynes 2001). In Lemdubu they are most prevalent in the top two spits but occasional examples are found down to Spit 17 (Table 9.5). The individuals recovered are small in size and few in number and it seems likely that they were scooped up when freshwater was being collected and then brought to the site inadvertently in the water containers. The terrestrial snails are damp forest dwellers and their overall abundance may be taken as a general indication of the prevalence of wet forest in proximity to the cave. Low quantities of land snail are found in spits 28-24, dated to between ca. 27,000 and 23,000 cal BP (Fig. 9.9, Table 9.5). Terrestrial molluscs disappear almost entirely from Spit 22 to 10, probably reflecting drier conditions and less dense vegetation around the

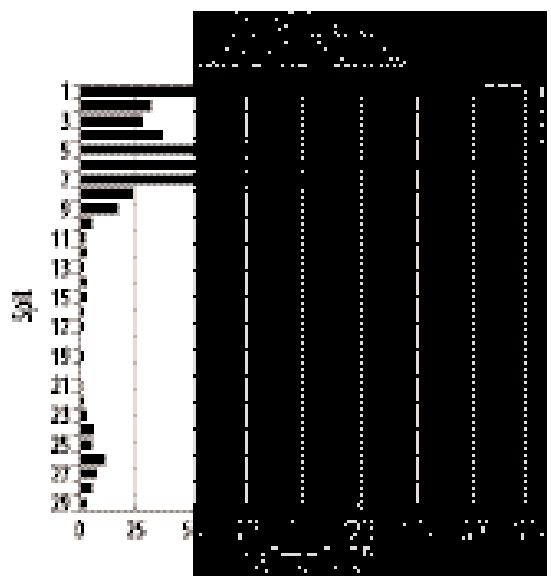

Figure 9.9 Liang Lemdubu: Test Pit C, raw weights (g) of terrestrial and freshwater molluscs 


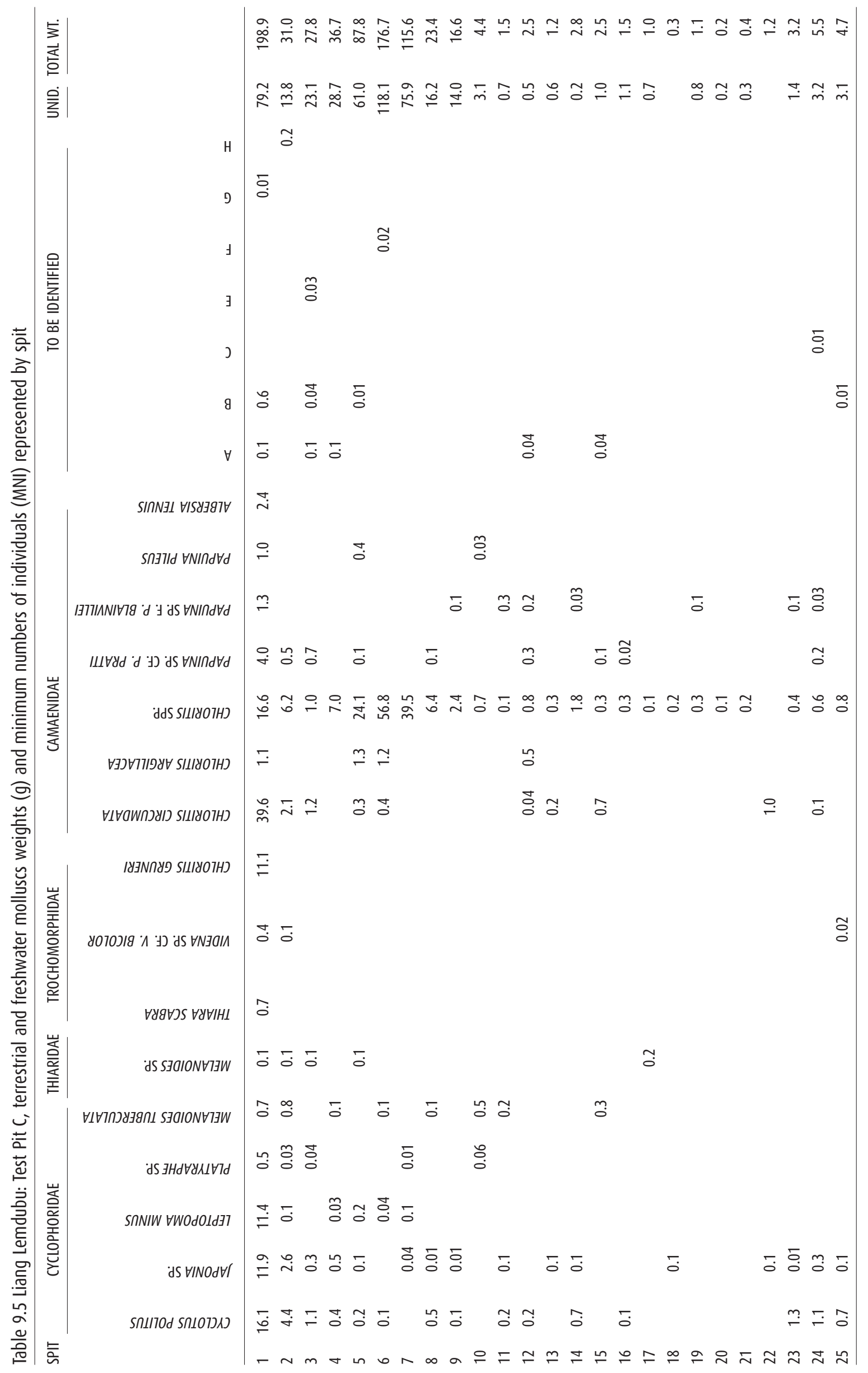


cave through the terminal Pleistocene. From Spit 9 numbers begin to rise again, with a dramatic increase from Spit 7 to the top of the deposit.

The dominant terrestrial snail genus is Chloritis spp. Judging from the size of the fragments, most of the pieces identified as Chloritis spp. were probably C. gruneri, however they were too broken to make identification to species possible. A large proportion of the unidentified snails were also likely to be C. gruneri.

The way in which the terrestrial snails entered the cave is open to question. They may have been brought into the cave attached to freshly cut vegetation used by the cave occupants as sitting mats, bedding or for wrapping food. Our field assistants commonly cut palm leaves and placed them on the floor of the cave to sit on while sorting or resting during breaks, or to produce a clean surface to prepare or serve food. The peak in land snails in Spits 7-5 compared with Spits 4-2 may indicate that wetter conditions and denser vegetation prevailed during the early Holocene. Alternatively, it may be that vegetation was reduced in the late Holocene following forest clearance for gardening (represented by Spits 1-4). Chloritis gruneri is a large species which could possibly have been brought in as food. If some of the terrestrial molluscs were food species, their decline at this time may indicate their replacement in the diet by estuarine species after the establishment of fully estuarine conditions (reflected in the fauna in Spit 4 and above). Distinguishing between these different scenarios is not possible on the basis of the available data.

\section{Vertebrate fauna}

The Liang Lemdubu excavation produced a large quantity of bone, with especially high densities encountered in the lower levels of Test Pit C (Tables 9.2 and 9.3). As observed also in the Liang Nabulei Lisa sequence (Chapter 7 , this volume), the vertebrate fauna from the uppermost deposit in Lemdubu contrasts strongly in physical condition and taxonomic composition with that from the lower part of the sequence. Essentially, bone from the upper levels is more heavily burnt and fragmented, and includes a wide range of animal groups but without any overwhelming pattern of dominance. In contrast, bone from the lower levels is less fragmented and less often burned, and is dominated by the remains of only one family, the Macropodidae.

\section{Analytical methods}

All samples were washed in a fine-mesh sieve and air dried. Bone artefacts were separated from the remaining bone material at this stage; these are reported by Pasveer in Chapter 11 of this volume.

The analytical methods essentially follow those described for the treatment of the Nabulei Lisa assemblage (see Chapter 7 for details). The critical objectives were as follows:

1) to determine the range of species present;

2) to establish the pattern of distribution of each species through the sequence; and

3) to estimate the relative abundance of the major species, both within each unit (interspecific) and through the sequence (intraspecific).

The physical condition of the assemblage was documented in terms of the proportions of four different burning categories, as described in Chapter 7.

\section{Vertical distribution and preservational state of bone}

The vertical distribution of bone is shown in Figure 9.10a and the bone weights adjusted for spit volumes in Figure 9.10b (Table 9.3). Peak values for bone are observed in Spits 24-25; however, as explained above, this is probably an artefact of the heavily cemented condition of bone in these levels. Ignoring this artificial peak, the true maximum values are observed at two points in the sequence: a sharp peak at Spit 10, and a broad peak centred on Spit 20. Relatively smaller quantities of bone were recovered in the uppermost levels of the site, in Spit 6 and above, and at the base of the sequence, below Spit 27. 
Three main stratigraphic zones are distinguished by the proportion of bone in each burning class (Fig. 9.11). Bone from the uppermost 11 spits shows a high proportion of burning, with calcined bone accounting for $3-17 \%$ of the total bone. The 'lightly burnt' category is particularly prominent in these levels. Between Spits 12 and 26 there is a marked decline in the proportion of the three burnt categories; unburnt bone makes up $60-80 \%$ of the total remains in these levels. Below Spit 26 less than 10\% of the bone is burnt.

The bone is moderately well preserved throughout the sequence, with little indication of differential degradation. Material from the upper levels of the sequence (in Spit 11 and above) appears more highly fragmented than that from the lower levels. The greater degree of fragmentation and burning in the upper part of the deposit is likely to be causally related. In the lower levels, the bone is often thinly coated with a layer of calcium carbonate and fine sediment. In Spits 25-26, the encrustation is more extensive and there are several chunks of 'bindstone' made up of densely packed bone fragments, thin layers of travertine, and cemented cave earth.

\section{Origin of the remains}

The preponderance of medium- to large-bodied animals such as macropodids, possums and large reptiles (Fig. 9.12), indicates that the Lemdubu fauna is predominantly derived from human activity, rather than being the product of non-human carnivore or raptor activity. The scarcity of tooth marks on the remains and the lack of rounding of fracture edges on all but a few specimens, also lend support to this view. This inference applies to all spits down to Spits 28 or 29. In contrast, the basal Spits 30 and 31 contain a higher proportion of smaller birds and mammals and may be derived wholly or in part from non-human activity. The fact that the lowest stone artefact was recovered from Spit 29 supports this view.

Material from the lowermost levels of human occupation (Spits 25-28) is noticeably less fragmented than that from the higher levels. In addition, the preserved fragments of 'bindstone' show several examples of anatomical association
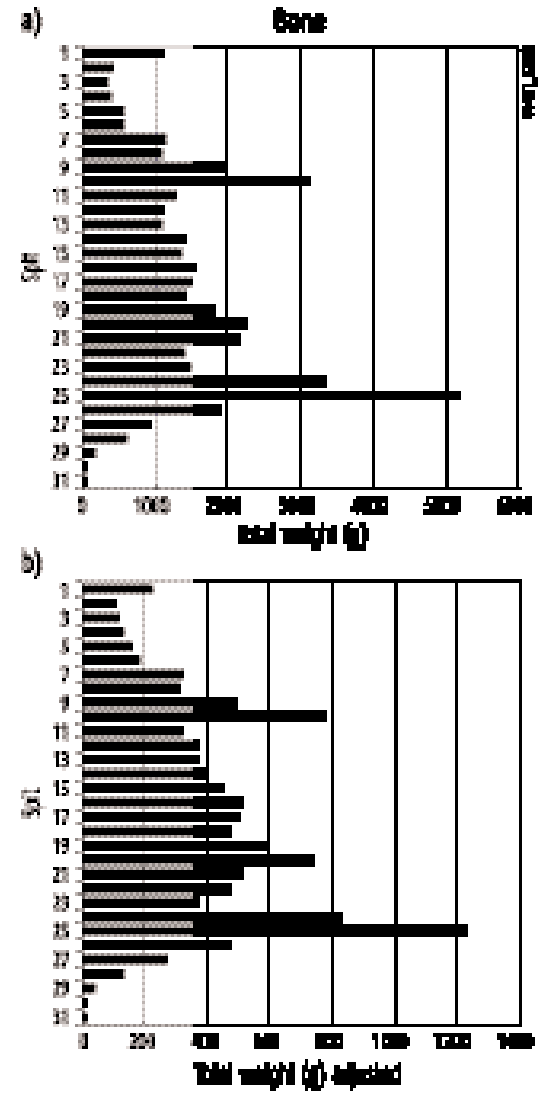

Figure 9.10 Liang Lemdubu: Test Pit C, a) raw weight (g) of bone through the sequence $b$ ) adjusted weight $(g$ ) of bone through the sequence

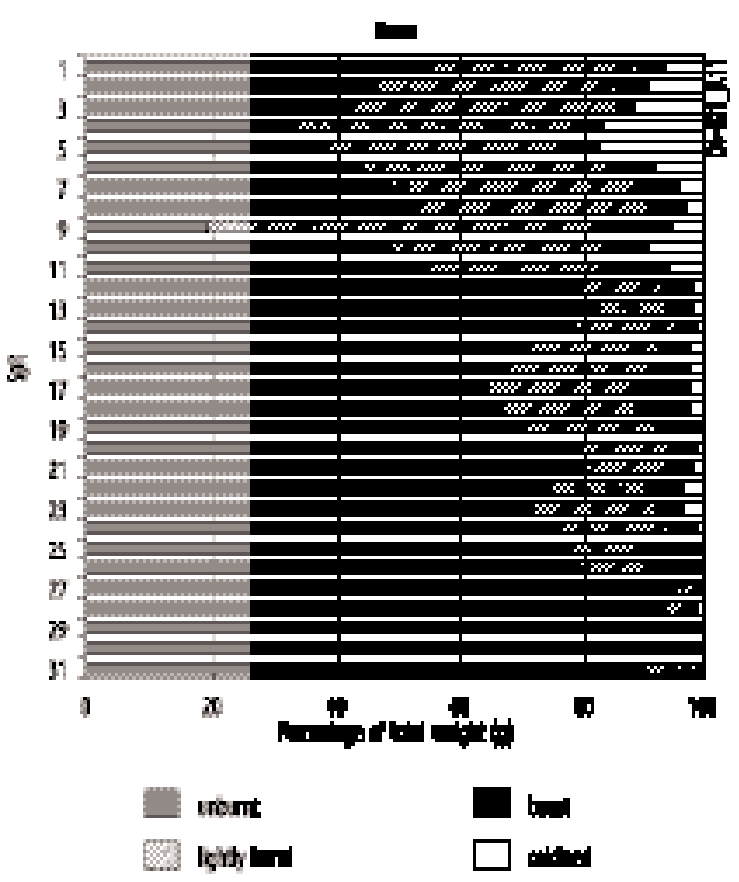

Figure 9.11 Liang Lemdubu: Test Pit C, percentage of total bone weight in each burning class 


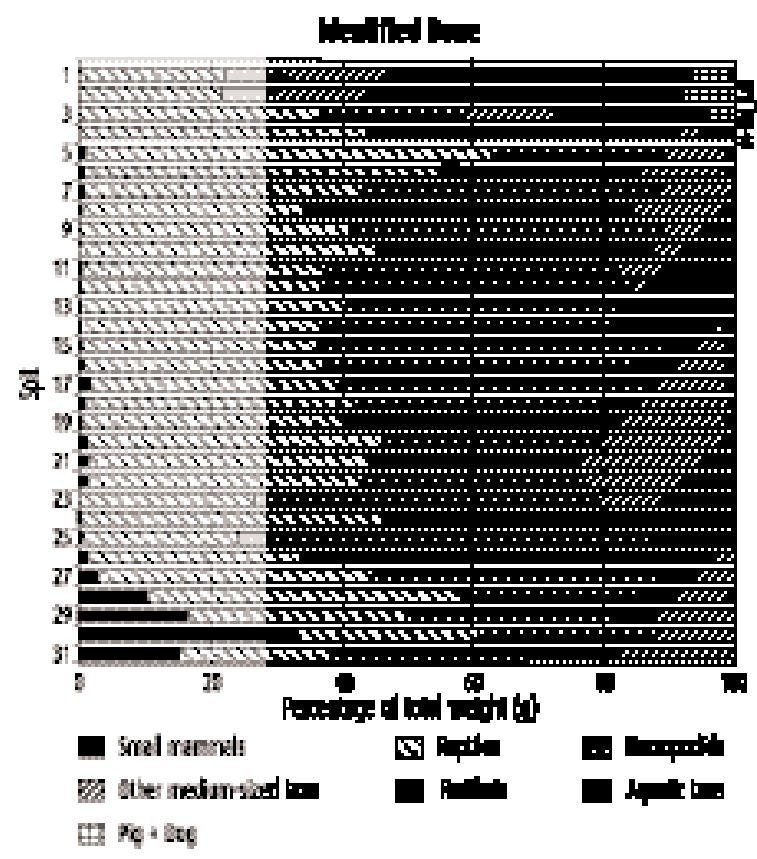

Figure 9.12 Liang Lemdubu: Test Pit C, summary of taxonomic categories (weight \%) within the vertebrate faunal remains. Much of the small mammal category is likely to be derived from raptor use of the site. The 'reptile' category is dominated by large goannas and pythons of skeletal elements, most notably among bones of the lower leg and hindfoot. The articulation of these elements suggests that little effort was being made to extract all available protein from these carcasses, and this in turn, may suggest an abundance of animal foods at that period in the history of cave occupation.

In all levels, some of the smaller mammal remains, including the occasional bones of smaller rodents and bats, might be derived from other sources including the regurgitated pellets of predatory birds roosting in the cave. However, as these are scattered through the sequence (Fig. 9.12), they do not influence the overall composition of the fauna.

\section{Species distributions}

The taxonomic composition of the Liang Lemdubu archaeological fauna was reported by O'Connor et al. (2002). NISP and weight data for all identified specimens are presented by spit in Appendix 9.3. Aplin and Pasveer (Chapter 3, this volume) document various subsequent changes in identifications and taxonomic nomenclature. Changes in nomenclature chiefly affect the murid rodents, where recent taxonomic revisions have led to the recognition of some new species, and the reassignment of others into different genera. Changes in identification reflect more detailed study by Aplin of some groups since the previous publication; these principally concern the peroryctid bandicoots and the rodents. The other significant change concerns the phalanges (foot bones) previously reported as belonging to a large 'megafaunal' species of kangaroo, tentatively referred to the genus Macropus. Access to better comparative material has now clarified that these specimens are from a species of Casuarius, probably C. casuarius (see Chapter 3 for details).

The Lemdubu faunal assemblage includes many taxa that are not recorded from the contemporary fauna of the Aru Islands. These include three macropodids (Macropus agilis, Thylogale stigmatica, and Dorcopsis sp.), two or three bandicoots (Isoodon macrourus, a previously unknown taxon, and possibly Echymipera kalubu), and the Short-beaked Echidna (Tachyglossus aculeatus). Other additions are a Native Cat (Dasyurus albopunctatus), several small rodents (Rattus sordidus, Pogonomys sp., Pseudomys sp. cf. P. nanus, Melomys sp. cf. M. burtoni), a medium-sized rodent (Parahydromys asper) and a small megachiropteran species (Dobsonia sp.).

The Lemdubu fauna contains the same four species of macropodids as are recorded in the Nabulei Lisa fauna. Only one of these is found on the Aru Islands today - Thylogale brunii, a small, rainforest dwelling pademelon. As reported previously in $\mathrm{O}^{\prime}$ Connor et al. (2002), a second group of Thylogale specimens compares most closely as a group with modern specimens of T. stigmatica. However, the archaeological sample shows greater size variation than would be expected within a single population and may include two closely related taxa. Thylogale stigmatica today is polytypic, with two or more subspecies usually recognized. Unfortunately, as it was not possible to allocate many of the less complete specimens to either the larger or smaller form of T. stigmatica, the two groups were not distinguished in the analysis. In Eastern Australia, Thylogale stigmatica is an 
inhabitant of rainforest margins and wet gallery forests. The other macropodids are a true grassland/savannah wallaby, Macropus agilis, and an inhabitant of dense rainforest, Dorcopsis sp.

The changing proportional representation of the three most important species is illustrated by percentage weight of bone in Figure 9.13, and by NISP in Figure 9.14. Numerically, the two Thylogale species together make up the greater part of the macropodid remains throughout the sequence. Thylogale brunii shows two peaks in abundance: one centred on Spits 18 to 24, and the other on the uppermost four spits. In contrast, T. stigmatica is most abundant in the lowermost part of the deposit and between Spits 17 and 5 . Macropus agilis also varies in abundance, with the lowest quantities in the upper three spits, the highest quantities between Spits 4-18, and intermediate values in Spit 19 and below. Dorcopsis sp. is represented by a single specimen: a very worn lower premolar, from Spit 24 . This taxon is too poorly represented to register in the graphs.

The increased quantities of the savannah dwelling M. agilis between Spit 18 and Spit 4 suggests drier and more open conditions during this period. This inference is supported by the reduced abundance of $T$. brunii relative to T. stigmatica during this period. Where the two species occur in regional sympatry today, in the Trans-Fly region of New Guinea, it appears that T. brunii tends to occupy the core rainforest habitats, whereas T. stigmatica is perhaps pushed into rainforest margin habitats.

Four species of bandicoots are probably represented in the Lemdubu assemblage, compared with a single species in the modern fauna. The sole surviving taxon, Echymipera rufescens, is represented throughout the deposit but is only dominant in the uppermost levels. Echymipera kalubu is tentatively identified from Spits 3-4 only. Both species of Echymipera occur today in lowland rainforest habitats on the New Guinea mainland. Isoodon macrourus, a species that is broadly associated with savannah grassland habitat in New Guinea and northern Australia (Flannery 1995), is present throughout the deposit but with peak values in Spits 17-25 (Fig. 9.15). A fourth bandicoot taxon, an unnamed taxon of uncertain ecological significance, is present in most spits between Spit 18 and Spit 27, with sporadic occurrences in higher levels (Spits 6 and 14). This taxon is also represented in Nabulei Lisa.

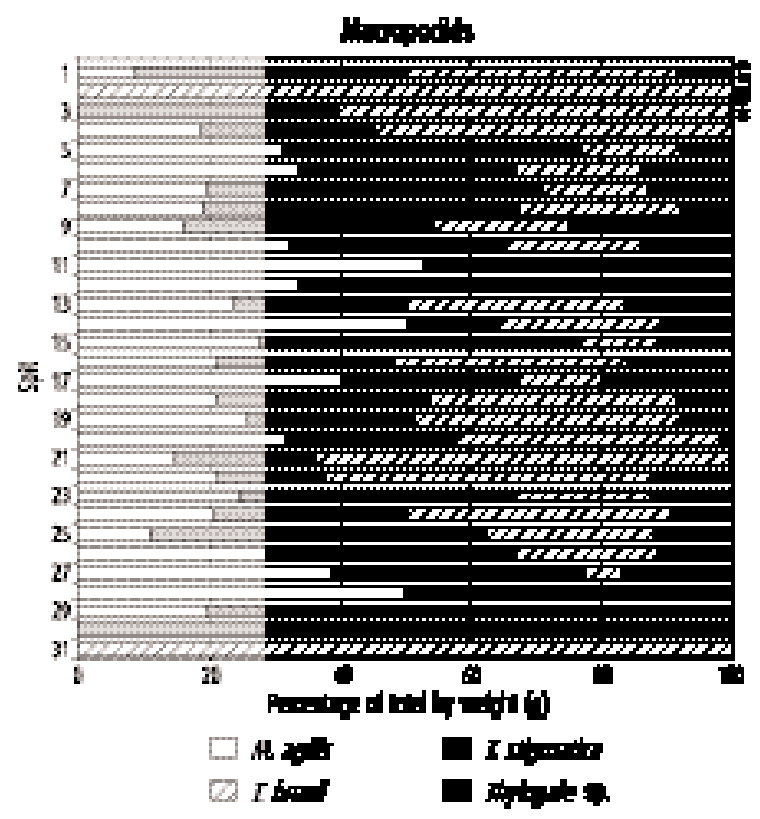

Figure 9.13 Liang Lemdubu: Test Pit C, the changing proportional representation (weight \% of bone) of the macropodids through the sequence

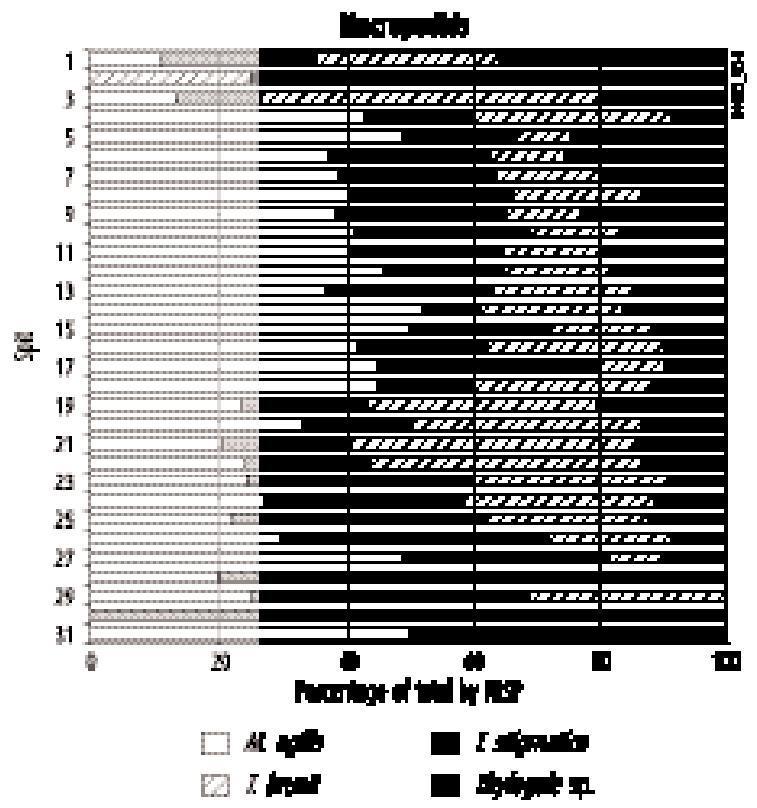

Figure 9.14 Liang Lemdubu: Test Pit C, the changing proportional representation (NISP) of the macropodids through the sequence 
Four species of possums are represented in the assemblage. All are part of the contemporary fauna of the Aru Islands. The Spotted Cuscus, Spilocuscus maculatus, is present in almost all excavated spits, with the highest quantities in the lower part of the deposit (Spits 18 and below) and in the uppermost levels (Fig. 9.16a). Two smaller cuscuses, Phalanger gymnotis and P. mimicus, also occur through the sequence. Phalanger mimicus shows a similar pattern to that of S. maculatus, with greater quantities in the lower part of the deposit (Fig. 9.16b). Phalanger gymnotis occurs more sporadically through the deposit and is generally less abundant than the other cuscuses (Fig. 9.16c). The Striped Possum, Dactylopsila trivirgata, is poorly represented by comparison, with single fragments in each of Spits 1 and 9. All four species are indicative of forest habitats. Phalanger gymnotis has not been recorded outside of rainforest habitats. The remaining species are more adaptable and occur today in a variety of forest types including riparian forests and relatively open woodlands. The decrease in abundance of S. maculatus and P. mimicus above Spit 19 is compatible

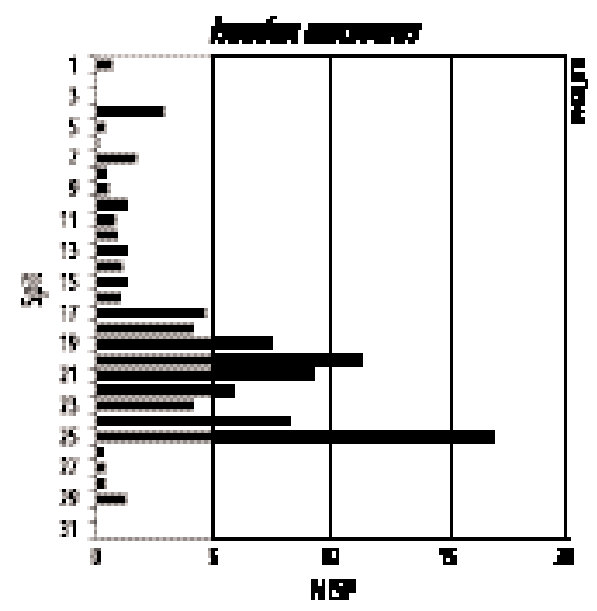

Figure 9.15 Liang Lemdubu: Test Pit $\mathrm{C}$, the changing proportional representation (NISP) of the bandicoot Isoodon macrourus through the sequence with the suggestion that the local vegetation was drier and more open from that time through until the more recent period represented by Spits 1-4.

Echidna (Tachyglossus aculeatus) is represented in most levels from Spits 25 to 5 (Fig. 9.17), with slightly higher quantities below Spit 18 than above (but with a localized peak in Spit 9). This taxon is absent from the Aru Islands today, despite it being present in both northern Australia and southern New Guinea.

The Lemdubu assemblage includes a limited quantity of small mammal remains. These are concentrated below Spit 10 and include examples of six or seven mammal species, such as Myoictis wallacei, another smaller dasyurid taxon, and five murid rodents. The murids include: Parahydromys asper, a partially
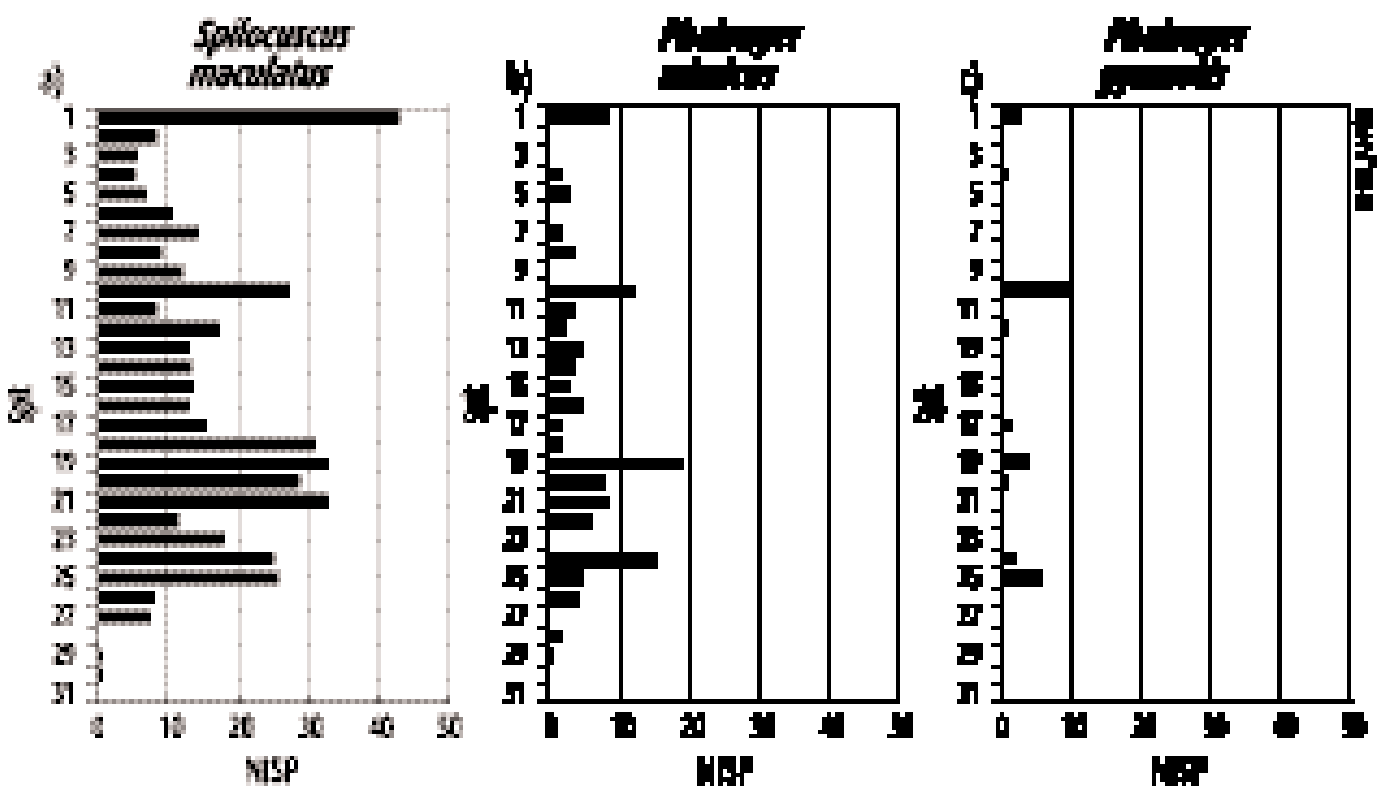

Figure 9.16 Liang Lemdubu: Test Pit C, distribution and proportional representation (NISP) of a) the Spotted Cuscus, Spilocuscus maculatus b) Phalanger mimicus and c) Phalanger gymnotis through the sequence 
aquatic species found only in the lowermost part of the site; Pogonomys sp., a rainforest dwelling tree mouse found in Spits 30 to 13; Rattus sordidus, a tropical grassland taxon found in Spits 28 to 11; and species of Pseudomys (cf. P. gracilicaudatus group), represented by a few specimens only. The few larger murid specimens are all referrable to Uromys caudimaculatus, a highly adaptable species that occurs across a variety of habitat types.

Megachiropteran bats (family Pteropodidae) are present in virtually all samples. They show a minor peak in abundance in the lower levels, culminating in Spit 19 (Fig. 9.18), and a larger peak in Spits 1-3. The bulk of the more diagnostic material is referrable to Dobsonia moluccensis. However, at least some of the material is derived from a smaller species of Dobsonia. The most likely candidate is $D$. viridis, a species known from the nearby Kei Islands (Aplin and Pasveer, Chapter 3, this volume).

The remains of introduced mammal species are confined to the upper four spits. Pig bones and teeth occur in Spits 2-4, whereas dog is represented exclusively in Spit 2. Although no deer remains were found during excavation, bones and teeth of Rusa timorensis were collected from the surface of the site.

Snakes are well-represented throughout the Liang Lemdubu sequence; in most spits they account for around $20 \%$ of all bone (Fig. 9.19). Almost all of the snake remains come from moderately large snakes belonging to the Boidae (pythons), with fewer examples of other groups including Colubridae. In view of the high meat weight to bone ratio of these large pythons they must have made a regular and important contribution to the diet. Monitors (Varanus spp.) are also represented in most levels, with peak values between Spits 19-25 and in Spit 10 (Fig. 9.20). Most varanid remains are from moderate to large-bodied individuals. Today, the only large Varanus found in the Aru Islands is the semiaquatic $V$. salvator. However, under drier conditions and with land connections through to northern Australia, it is possible that other largebodied species were represented, including $V$. gouldi, V. panoptes and V. mertensi.

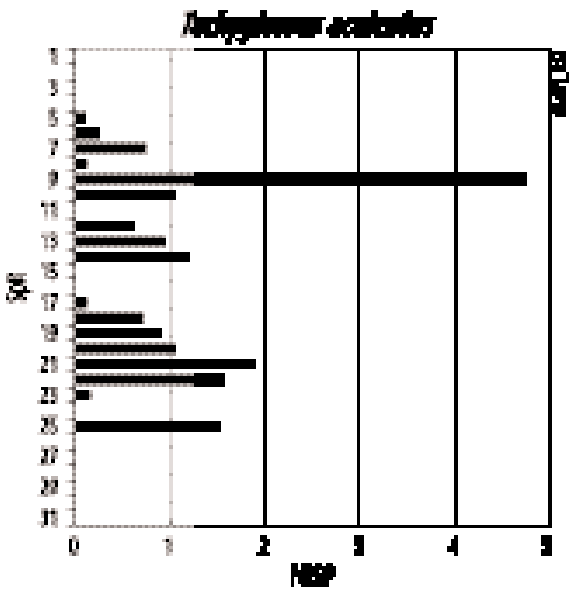

Figure 9.17 Liang Lemdubu: Test Pit C, distribution and proportional representation (NISP) of Echidna (Tachyglossus aculeatus) through the sequence. This species is represented in most levels from Spits 25-5

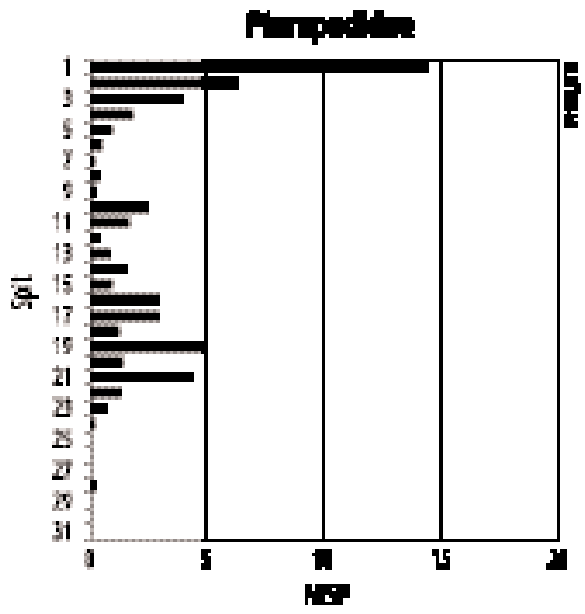

Figure 9.18 Liang Lemdubu: Test Pit C, distribution (NISP) of Pteropodidae bats through the sequence

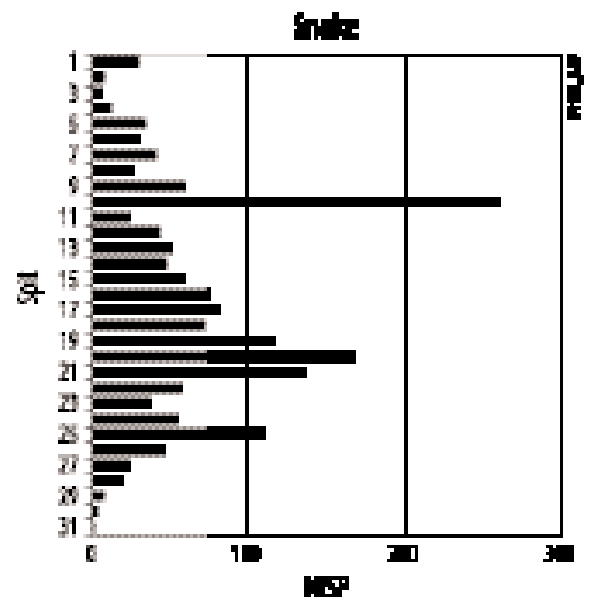

Figure 9.19 Liang Lemdubu: Test Pit C, distribution of snakes through the sequence (NISP) 


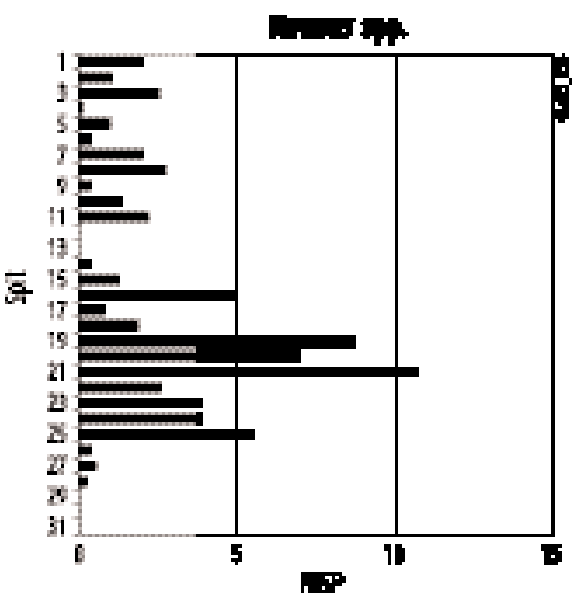

Figure 9.20 Liang Lemdubu: Test Pit C, distribution of Varanid lizards through the sequence (NISP)
Other reptiles represented in the Lemdubu fauna include skinks (Scincidae) and dragons (Agamidae). A dentary fragment from Spit 26 is tentatively identified as Tiliqua gigas. The agamid material has not been closely examined. However, the fact that this group peaks in Spits 1-5 and Spits 16-25 suggests a likely predominance of wet forest taxa such as Goniocephalus spp. over drier country agamids (e.g. Amphibolurus spp., Chlamydosaurus sp. and Lophognathus spp.).

Turtle bone is present in three spits only: Spits 1, 14 and 29. All fragments probably come from one or more species of freshwater cheluid turtles rather than from any of the larger-bodied marine species. Frog bone is present in small quantities down to Spit 13.

Small quantities of bird bone are scattered through the deposit. This includes recognizable examples of cassowary bones in Spit 3 and Spits 20-21. Although three species of cassowary are found in New Guinea (C. unappendiculatus, C. bennetti, and C. casuarius), only C. casuarius subspecies aruensis is found in the Aru Islands today. Cassowaries are hunted in the forest around Lemdubu today and the eggs collected for food.

Cassowary eggshell fragments were found in Spits 1-5 and 17-20 of the Lemdubu excavation (see Clarke and Miller, Chapter 13, this volume). Identification of the eggshell from Spits 17-20 as cassowary (Casuarius sp.) rather than emu (Dromaius novaehollandiae) requires further comment. As Aru was connected to northern Australia in the late Pleistocene, and the other terrestrial fauna from the lower levels of the site suggest savannah grassland conditions prevailed at this time, it is possible that the area supported populations of emu, perhaps living in regional sympatry with one or more cassowary species. Emu and cassowary eggshell are difficult to tell apart on the basis of morphology. Fortunately, eggshell of the two groups differs in the rate of amino acid racemisation and in their carbon stable isotope signals. As described by Clarke and Miller (Chapter 13, this volume), the rate of racemisation in the samples of egg shell from Lemdubu is comparable with that documented in samples from Toé and Kria Caves in the Bird's Head of Indonesian Papua. These sites contain exclusively closed forest fauna, and it is certain that the Bird's Head eggshell is from a species of cassowary (Pasveer 2004). Further, the carbon stable isotope results on the

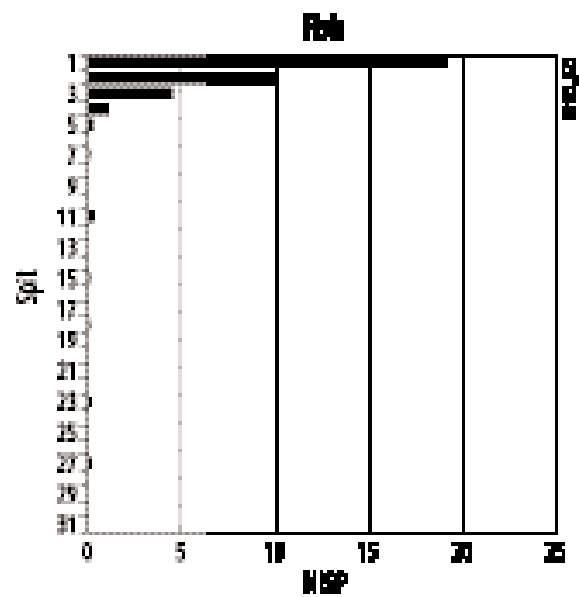

Figure 9.21 Liang Lemdubu: Test Pit C, distribution of fish bone through the sequence (NISP) eggshell from Lemdubu indicate a bird whose diet consists of less than $20 \%$ tropical grasses (Clarke pers. comm).

All cassowary eggshell in the deposit must derive from eggs brought into the site by people as food. Although no information is available on breeding times of C. casuarius in Aru, in north Queensland breeding 'occurs mostly in the dry season' coinciding 'with the average maximum availability of fruit in the forest' (Crome 1975:9, 13). The archaeological eggshell fragments presumably demonstrate use of the site in the dry season. The absence of eggshell fragments between Spit 6-16 and below Spit 20 is noteworthy; coupled with the absence of 
cassowary bone in the same levels, it suggests a genuine scarcity or absence of remains of this prized game item through much of the occupation of the site.

Fish remains are concentrated in the uppermost four spits, with scattered examples from lower levels (Fig. 9.21). The sample from the upper levels includes both freshwater (e.g. Ariidae) and marine (e.g. Scariidae) taxa.

\section{Plant material}

Charcoal was sparse below Spit 2 but occurs in measurable quantities down to Spit 10 (Tables 9.2 and 9.3). Small flecks of what appear to be charcoal were found after wet sieving in all spits, down to the base of the site, but as they were not recovered in situ these fragments were considered unreliable for dating. In view of the large quantity of burnt bone and shell in units below Spit 3, the paucity of charcoal is presumed to be due to taphonomic factors leading to the progressive destruction of charcoal over time.

The only seeds preserved were those of Celtis philippinensis which were found in Spits 1-11 (Table 9.2). Celtis seeds are commonly found in archaeological sites and are usually assumed to enter sites independently of people. They may enter incidentally attached to branches destined for firewood or other purposes. Celtis grow close to the entrances of Lemdubu today, however, the faunal data demonstrate that during the Pleistocene vegetation around the cave was much more open. It is significant that Celtis seeds were not recovered from the lower spits coinciding with this period of open vegetation.

\section{Palaeoenvironmental Interpretation}

The combined molluscan and vertebrate faunal analysis provides a detailed picture of environmental changes and human responses in the vicinity of Liang Lemdubu over the past 28,000 years. The sequence of changes is most conveniently described as a succession of three time periods. However, the exact delineation of these periods should be regarded as somewhat arbitrary.

\section{Spits 31-19 (ca. 28,000-ca. 20,000 cal BP)}

The basal two or three spits produced a small quantity of bone and no clear evidence of human activity; these may predate the earliest occupation of the site. However, from Spit 28 on, there is abundant evidence for human activity. From the composition of the vertebrate fauna from this period it is clear that the dominant vegetation community in the vicinity of the site was relatively dry and open vegetation, probably savannah woodland with grassy understorey. This supported a range of species today found in savannah woodland and grasslands of the Trans-Fly and across northern Australia, including Macropus agilis, Isoodon macrourus and Rattus sordidus. However, the presence in the same levels of many species found today in rainforest or dense gallery forest (i.e. Thylogale spp., Dorcopsis sp., Echymipera rufescens, Poponomys sp., Spilocuscus maculatus and Phalanger spp.), also points to the presence in the area of substantial patches of wetter, denser vegetation. These communities presumably occupied topographic lows in the karst landscape, including the major drainage features.

Exactly how much of the area was occupied by each of these vegetation communities is difficult to judge. However, the fact that the two largest of the obligate rainforest animals, namely Dorcopsis sp. and Casuarius sp., are recorded only sporadically through this period suggests either that the wetter forest communities were of insufficient size and continuity to support viable populations of larger animals, or that these patches were subject to early and intense hunting pressure such that the larger animals were rapidly extirpated. If the latter process took place, then it left no archaeological signature, at least not in the excavated part of Lemdubu. 


\section{Spits 18-5 (ca. 20,000-ca. 9000 cal BP)}

This zone is characterized by an increase in the relative abundance of the dry community taxa, and a corresponding fall in those taxa associated with wetter, denser habitats. Although the transition point between this zone and the last is set at the boundary between Spits 18 and 19, the transition between the two zones is really a gradual one, with different taxa most likely responding to common stimuli at different times and rates. Thus T. brunii, a taxon of deep rainforest habitat, begins to decline in relative abundance from peak values in Spits 20-21, while T. stigmatica, a taxon of forest edge habitats, does not increase until after Spit 18. Macropus agilis, a true savannah grassland wallaby, is relatively more abundant in Spit 18 and above. The two cuscuses, S. maculatus and P. mimicus, decrease in abundance after Spit 19, as do varanids and megachiropteran bats. In contrast, cassowary eggshell is present through to Spit 17. A somewhat anomalous trend is the decrease in abundance of I. macrourus, a bandicoot of tropical grassland habitats, above Spit 17.

The overall impression, then, is that the rainforest patches probably declined in both extent and quality through this period, perhaps starting from the time Spit 20 was deposited onwards. This may have occurred as a result of climatic deterioration, or through increasing pressure on these habitats as a consequence of hunting and/or general exploitation of forest products. The timing of this change, which corresponds with the peak of the last glaciation, perhaps lends weight in favour of a climatic explanation.

\section{Spits 4-1 (ca. mid-Holocene?-present)}

This period is characterized by numerous changes in the faunal assemblage. Most conspicuous is the marked increase in the quantities of shellfish remains and in fish bone, clearly marking the emergence of a marine drainage system within the sungai and their tributaries. Other changes include a marked decrease in the relative abundance of wallabies relative to all other groups, an increase in the abundance of $T$. brunii relative to the other macropodids, and a marked increase of both megachiropteran bats and cuscuses. Cassowary bone and eggshell reappear during this period. All of these changes point to an expansion of closed rainforest habitats at the expense of open savannah communities. The addition of pig and dog remains to the assemblage also represents a significant change, indicative of external cultural influence.

The general composition of the vertebrate fauna in this zone is thus consistent with the contemporary habitat of the Aru Islands. In this light, the continued presence of various savannah elements such as M. agilis and I. macrourus into these levels begs comment. Two possibilities spring to mind. The first is that populations of various savannah dwelling taxa persisted long after the general expansion of rainforests. The second is that the upper levels of Lemdubu are disturbed to the extent that a small quantity of material from the lower levels has moved up into the uppermost spits. One observation that would favour the latter view is the fact that M. agilis and I. macrourus both disappear before $7700 \mathrm{BP}$ in the extended Nabulei Lisa sequence.

\section{Human Skeletal Material}

Human bones which appear to constitute a single burial were recovered from Spits 18-23. The remains are described in detail by Bulbeck (Chapter 12, this volume). The burial is capped by a large flat slab of limestone which occurs in Spits 17 and 18, and which can be seen in the section in Figures 9.5 and 9.6.

The burial is judged to be that of a female. Although the bones are in approximate anatomical position, occasional bones are misplaced or misaligned, and the foot and hand bones are missing altogether. This arrangement suggests a secondary burial; however, it is also possible that it is a primary burial that has been subject to inquest or disturbance after burial. 
Dating the Lemdubu burial was essential both to provide an age for the burial itself and in order to ascertain the degree of stratigraphic disturbance within the site. On stratigraphic grounds, it appeared that the body or skeleton had been placed in a hole dug to a depth of approximately $25-30 \mathrm{~cm}$ from Spit 18 into the surface of Spit 19, and the capping stone placed on top (with subsequent accumulation of the sediment of Spit 18 and 17). The alternative scenario, that the burial and capping stone had been placed at this depth from much higher in the sequence, potentially even from the late Holocene unit, would have major implications for potential mixing of cultural materials in all spits above the burial. However, the clear patterning in the vertebrate and invertebrate faunal remains argues against major disturbance of this kind, as does the evidence for the late Pleistocene age of the burial itself, as indicated by the ESR dating results.

\section{Bone Artefacts}

Thirty-seven bone artefacts were recovered from the excavation, of which 34 occurred in Spits 1 to 5, one in Spit 16, and two in Spit 24 (Fig. 9.22). Pasveer (Chapter 11, this volume) provides a full description and analysis of the bone artefact assemblage from Lemdubu. The assemblage comprises unipointed and spatulate artefacts, but within each of these categories there is great variability. Many artefacts are manufactured on fragments of long-bone shaft, such as wallaby fibulae. A high proportion of lightly burnt examples may indicate preparation or intentional selection of this material for bone artefact manufacture. The fact that all specimens found at Lemdubu were 'fragments' makes it likely that the artefacts were used and broken on site. It would also seem likely that maintenance activities,

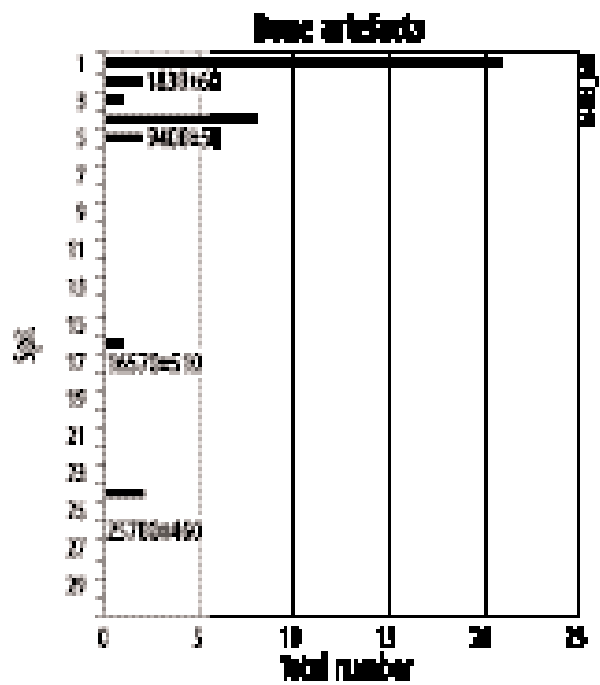

Figure 9.22 Liang Lemdubu: Test Pit C, distribution of bone artefacts through the sequence, also showing selected radiometric dates such as replacement or repair, took place on site given that mid sections (or butts) occur. A relatively high incidence of specimens with unpolished and undamaged tips may also indicate that primary manufacture took place at the cave, however, since no half-products or 'unfinished' specimens were found this remains uncertain.

Pasveer discusses possible functions for the bone artefacts from Lemdubu based on the usewear and damage they exhibit, and concludes that while the historical accounts from the Aru Islands emphasize the importance of bows and composite arrows as hunting weapons (Merton 1910:60), the wear patterns on the Lemdubu artefacts do not support their use as projectile tips. The Lemdubu assemblage display various combinations of damage and polish, often of quite high intensity. The presence of polish in general suggests a mode of use including repeated friction, and this is unlikely to accumulate on artefacts that are subjected to high velocity impact such as arrow tips or spear points. Pasveer concludes that the bone artefacts were most likely used for drilling holes or in engraving activities; the actions most likely to generate both polish and damage such as crushing or step fracturing of the tip. A similar conclusion was reached by Pasveer (2004) and Pasveer \& Bellwood (2004) for the bone artefacts from the Bird's Head of New Guinea and Northern Maluku, respectively. 


\section{Stone Artefacts}

Stone artefacts occurred throughout the excavation, generally in low numbers (Tables 9.2 and 9.3). The stone artefacts are described in detail by Hiscock in the following chapter (Chapter 10). The assemblage is essentially composed of small percussion struck flakes (Fig. 9.23), with a minor modified component represented by a few retouched/utilized flakes. An interesting change in dominant lithology occurs within the sequence, with silicified limestone dominant in the upper five spits and cherts present in larger proportion in the lower levels. One interesting and unusual feature of the assemblage is the near absence of both cores and micro-debitage of the kind produced during flake manufacture or retouch. This may indicate that manufacturing took place off site, i.e. that the flakes in the assemblage were brought into the site, ready-made for use. Most artefacts occur between Spits 7 and 10 at the terminal Pleistocene/Holocene boundary. The peak value for stone artefacts in Spit 1 is due to the presence of a single large specimen.

The change in lithology may be due to changes in the local site environment. It is possible that the source of the chert used to produce artefacts in the Pleistocene became inaccessible when present sea level conditions were established (thought to coincide with the deposition of Spit 4). Alternatively, it may simply be that there was a change in site function in the late Holocene, after which time the site was presumably used in much the same way as it is today, by hunterhorticulturalists with metal and bamboo tools. Hunters today use predominantly metal and sharp bamboo knives to skin and butcher their catch. While there is no indication of the appearance of metal in the site, we may presume from the dates for the upper three spits that metal tools were in general circulation by this time.
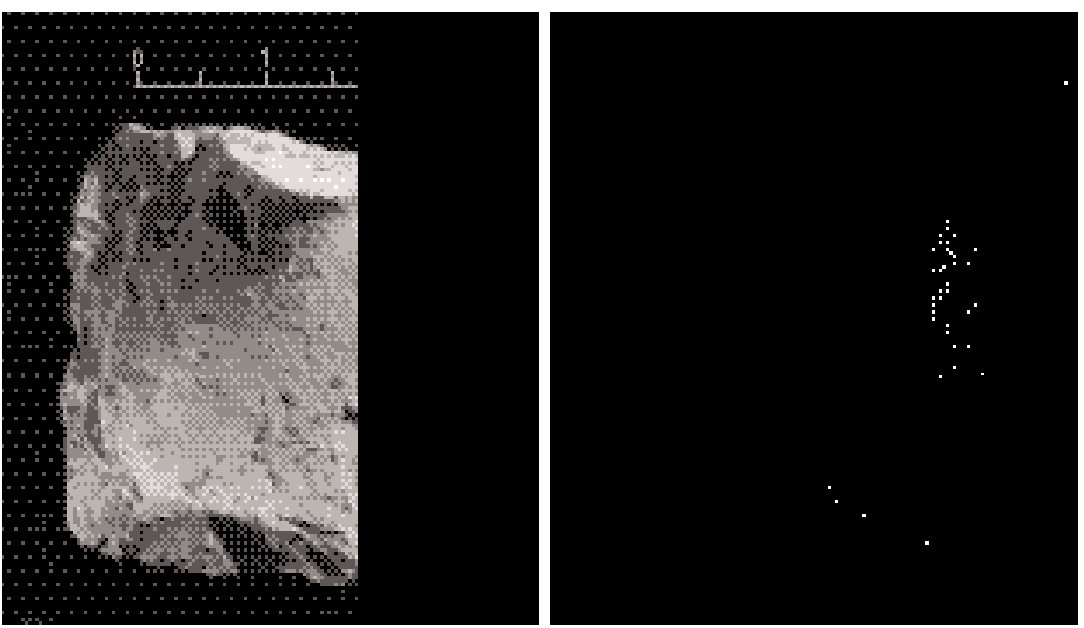

Figure 9.23 Liang Lemdubu: Test Pit C, typical small chert flake

\section{Pottery}

Aside from the historic porcelain and pottery vessels cemented to the natural flowstone platform in the central area of the cave, there was little pottery to be seen on the surface of the cave floor. Three sherds were recovered from the upper two spits in Test Pit C but were returned to Jakarta and were not included in the petrological analysis of the Aru sherds. The field records indicate that these were small body fragments of earthenware pots, and were calcite-quartz tempered. 


\section{Conclusions}

The lowest stone artefact at Liang Lemdubu is found in Spit 29. The earliest dated level with evidence for occupation is Spit 28, dated at 27,000 BP. As the fauna in Spits 30 and 31 is probably not humanly derived, it seems likely that the date of 27,000 years is close to the real age for initial human occupation at the site.

The initial occupation of Liang Lemdubu is considerably later than that documented from areas elsewhere in Melanesia and in northern Australia (O'Connor and Chappell 2003). This begs the question as to whether evidence for older occupation might be found with more extensive sampling of Lemdubu or elsewhere on the Aru Islands, or alternatively, whether the Aru Plateau may have been unattractive to human occupants of the wider region prior to 27,000 BP. Evidence from elsewhere in the region does suggest that the period prior to 28,000 BP was wetter than subsequently (van der Kaars 1991; van der Kaars et al. 2000), and it is probable that the Aru Plateau would have supported a rainforest community at that time. The Aru Plateau may have become more favourable for human occupation after 27,000 as drier conditions ensued and the vegetation opened up, producing more diverse habitats for an array of mammal fauna.

The Liang Lemdubu faunal sequence beginning 27,000 years ago, documents the presence on the late Pleistocene Kobroor Plateau of open savannah with denser, lusher vegetation present in pockets along watercourses and in other sheltered areas. The mammal fauna present at that time was basically similar to that found today in the Trans-Fly region of New Guinea and in parts of Cape York Peninsula, but included more species than either of these areas has today. People using the site at this time focussed their efforts on the procurement of the large-bodied Agile Wallaby (Macropus agilis) and several smaller wallabies (Thylogale spp.), with more casual acquisition of various medium-sized animals including cuscuses, bandicoots and pythons. Around 20,000 BP, the faunal assemblage changes slightly, with an increase in savannah elements at the expense of rainforest fauna. This may reflect a deterioration of climatic conditions associated with the glacial maximum or it might be related to a progressive deterioration of the rainforest patches over time.

The terminal Pleistocene saw the inundation of the Carpentarian Plain, the change to insular conditions, and the expansion of rainforest habitats across the Aru Islands. Human occupation of the cave and net sediment accumulation appears to have ceased entirely or been minimal during this time, at least in the area of Test Pit C.

In an earlier paper ( $\mathrm{O}^{\prime}$ Connor et al. 2002) we questioned whether widespread human abandonment may have been a response to the spread of rainforest in the early Holocene, and discussed this possibility within the context of hunter/gatherer responses to rainforest elsewhere in the tropical world (e.g. Bailey and Headland 1991; Roosevelt et al. 1996). The disappearance of the savannah species such as the Agile Wallaby, which appear to have been a significant component of the Pleistocene subsistence strategy, led us to question whether Aru may have represented a similar case to southwest Tasmania, where Kiernan et al. (1983) argued that 'recolonization of the region by forest tree species [in the Holocene] reduced the preferred habitats of the game species; game became scarce and humans also left' (see also Porch and Allen 1995:725). The excavation and dating of Liang Nabulei Lisa (Chapter 6, this volume) has demonstrated beyond doubt that Aru was occupied throughout the Holocene. If Liang Lemdubu was indeed abandoned at this time, it was perhaps as a response to local rather than regional changes. The cave may have been too remote from the sungai to make regular visitation worthwhile once the rich savannah plains were no longer a hunting drawcard. Alternatively, this chronostratigraphic gap may simply be a product of limited sampling in a large cave where material is unevenly distributed across the floor. 
The stone artefacts in Liang Lemdubu show little variation through time, with the exception of a change in dominant lithologies. Silicified limestone dominates the upper five spits, and below Spit 9 around $80-90 \%$ of all artefacts are made on chert. It may be that the source of the chert became inaccessible in the mid-late Holocene following sea level rise. As noted earlier, a similar situation has been reported in the southwest of Western Australia where offshore chert sources were drowned by post-glacial sea level rise and cease to be available after $6000 \mathrm{BP}$, and consequently late Holocene tools are predominantly made on other lithologies (Glover 1975; Pearce 1977). Alternatively, it may simply be that in the late Holocene the site was being used predominantly by 'horticultural' hunters who acquired and used stone on a much more expedient basis and probably also used metal tools.

One interesting and unusual feature of the stone artefact assemblage is the near absence of cores and very small flakes resulting from artefact manufacture or retouch, indicating that manufacturing took place off site, and the flakes in the assemblage were brought into the site for use. The highest numbers of artefacts occur between Spits 7 and 10, whereas bone weights are highest in Spits 24 and 25, following fairly fast on initial occupation of the site. However, the bone above Spit 12 is more heavily burnt and highly reduced, suggesting more intense use of the site and local resources - including stone - and perhaps more intense reduction of the bone to extract marrow.

The late Holocene spits (1-4) indicate a shift in the patterns of resource use and presumably site use. They contain pottery, dog and pig bones, and presumably reflect the arrival of agriculturalists. The non-domesticated fauna indicates a change in the environment around the site as well as hunting strategy. There is an increased use of marine resources obtainable from the sungai following post-transgressive sea levels. Specific, targeted hunting of wallabies declines. This may simply reflect species availability following the spread of wetter forests and the loss of the open savannah element, most prominently the Agile Wallaby. The decrease in wallabies is countered by an increased use of riverine resources, such as fish and shellfish, and of various lesser game items such as cuscuses and fruitbats. This phase of cave use may have looked much like the present-day use of the cave, which is predominantly by people with a horticulturally-based economy who use it on hunting trips or when passing through the karst on their way from one area of gardens to another. Wallace's (1869:343) observation of the interior groups of this area contrasts sharply with the faunal deposit from the Pleistocene levels of Liang Lemdubu, but sits more comfortably with the Holocene assemblage:

Now and then they get wild pig or kangaroo, but too rarely to form anything like a regular part of their diet, which is essentially vegetable ... e.g. plantains, yams, sweet potatoes and raw sago; sugar cane, betel nuts, gambir and tobacco. 


\section{References}

Ayliffe, L.K., P.C. Marianelli, K.C. Moriarty, R.T. Wells, M.T. McCulloch, G.E. Mortimer, and J.C. Hellstrom. 1998. 500 Ka precipitation record from south-eastern Australia: evidence for interglacial relative aridity. Geology 26:147-50

Bailey, R.C. and T.N Headland. 1991. The tropical rainforest: is it a productive environment for human foragers? Human Ecology 19(2):261-85.

Coleman, N. 1981. What Shell is That? Sydney: Lansdowne Press.

Crome, F.H.J. 1975. Some observations on the biology of the Cassowary in northern Queensland. Emu 76:8-14.

Flannery, T.F. 1995. Mammals of New Guinea (revised edition). Sydney: Reed Books.

Glover, J.E. 1975. Aboriginal chert artefacts probably from quarries on the continental shelf, Western Australia. Search 6:392-4.

Grün, R. 1989. Electron spin resonance (ESR) dating. Quaternary International 1:65-109.

Grün, R. 1995. Semi non-destructive, single aliquot ESR dating. Ancient TL 13:3-7.

Haynes, A. 2001. Freshwater Snails of the Tropical Pacific Islands. Suva: Institute of Applied Science, University of the South Pacific, Fiji.

van der Kaars, W.A. 1991. Palynology of eastern Indonesian marine piston-cores: a late Quaternary vegetational and climatic record for Australasia. Palaeogeography, Palaeoclimatology, Palaeoecology 85:239-302.

van der Kaars, W.A., X. Wang, P. Kershaw, F. Guichard, and D.A. Setiabudi. 2000. A late Quaternary palaeoecological record from the Banda Sea, Indonesia: patterns of vegetation, climate and biomass burning in Indonesia and northern Australia. Palaeogeography, Palaeoclimatology, Palaeoecology 155:135-53.

Kiernan, K., R. Jones, and D. Ranson. 1983. New evidence from Fraser Cave for glacial age man in southwest Tasmania. Nature 301:28-32.

Merton, H. 1910. Forschungsreise in den Sudostlichen Molukken (Aru- und Kei Inseln). Frankfurt am.M.: Senckenbergischen Naturforschenden Geschellschaft.

Monk, K.A., Y. De Fretes, and G. Reksodiharjo-Lilley. 1997. The Ecology of Nusa Tenggara and Maluku. Hong Kong: Periplus.

O'Connor, S. 1999. 30,000 Years in the Kimberley: A Prehistory of the Islands of the Buccaneer Archipelago and Adjacent Mainland, West Kimberley, Western Australia. Canberra: Archaeology and Natural History Publications, Research School of Pacific and Asian Studies, Australian National University. Terra Australis 14.

O'Connor, S., K. Aplin, M. Spriggs, P. Veth, and L.A. Ayliffe. 2002. From savannah to rainforest: changing environments and human occupation at Liang Lemdubu, the Aru Islands, Maluku, Indonesia. In A.P. Kershaw, B. David, N. Tapper, D. Penny, and J. Brown (eds), Bridging Wallace's Line: The Environmental and Cultural History and Dynamics of the Southeast Asian-Australian Region, pp. 279-306. Reiskirchen: Catena Verlag. Advances in GeoEcology 34.

O'Connor, S. and J. Chappell. 2003. Colonization and coastal subsistence in Australia and Papua New Guinea: different timing, different modes. In C. Sand (ed.), Pacific Archaeology: Assessments and Prospects. Proceedings of the International Conference for the 50th Anniversary of the First Lapita Excavation (July 1952), Koné-Nouméa 2002, pp. 15-32. Nouméa: Départment Archéologie, Service des Musées et du Patrimoine de NouvelleCalédonie. Le Cahiers de l'Archéologie en Nouvelle-Calédonie 15.

Pasveer, J.M. 2004. The Djief Hunters: 26,000 Years of Rainforest Exploitation on the Bird's Head of Papua Indonesia. Lisse: A.A. Balkema. Modern Quaternary Research in Southeast Asia 17.

Pasveer, J.M. and P. Bellwood. 2004. Prehistoric bone artefacts from the northern Moluccas, Indonesia. In S.G. Keates and J.M. Pasveer (eds), Quaternary Research in Indonesia, pp. 301-59. Lisse: A.A. Balkema Publishers. Modern Quaternary Research in Southeast Asia 18.

Pearce, R.H. 1977. Relationship of chert artefacts at Walyunga in south-west Australia, to Holocene sea levels. Search 10:375-7.

Porch, N. and J. Allen. 1995. Tasmania: archaeological and palaeo-ecological perspectives. Antiquity 69(265):714-32.

Roosevelt, A.C., M. Lima Da Costa, C. Lopes Machado, M. Michab, N. Mercier, H. Valladas, J. Feathers, W. Barnett, M. Imazo Da Silverira, A. Henderson, J. Silva, B. Chernoff, D.S. Reese, J.A. Holman, N. Toth, and K. Schick. 1996. Paleoindian cave dwellers in the Amazon: the peopling of the Americas. Science 272:373-84.

Wallace, A.R. 1869. The Malay Archipelago: The Land of the Orang-Utan and the Bird of Paradise. A Narrative of Travel, with Studies of Man and Nature. London: MacMillan. 


\section{Appendix 9.1: Liang Lemdubu: Test Pit C, Log of the Sediments from the Bulk Samples by Spit}

\begin{tabular}{|c|c|c|c|}
\hline SPIT & MUNSELL COLOUR & $\mathrm{pH}$ & DESCRIPTION \\
\hline 1 & Grey: 10YR 6/1-5/1 & 8.0 & $\begin{array}{l}\text { Very well sorted medium and fine silts with minor very fine sands (loose } \\
\text { unconsolidated powdery with no aggregates). Occasional 4-6mm angular to } \\
\text { subangular fine gravels of limestone dispersed. Occasional clasts }(<5 \mathrm{~mm}) \text { of } \\
\text { travertine. The broken shell and bone component are unweathered }\end{array}$ \\
\hline 2 & & 8.0 & No bulk sample \\
\hline 3 & Grey: 10YR 6/1-5/1 & 8.0 & $\begin{array}{l}\text { Very well sorted medium and fine silts, with minor very fine sands (loose } \\
\text { unconsolidated powdery with no aggregates). Occasional to frequent } 10-15 \mathrm{~mm} \\
\text { irregular nodular subrounded concretions of calcrete. Occasional large broken shell } \\
\text { and some bone to } 35 \mathrm{~mm}\end{array}$ \\
\hline 4 & Grey: 10YR 6/1-5/1 & 8.0 & $\begin{array}{l}\text { Very fine silts. Well sorted to very well sorted. Powdery and loose. Occasional } \\
\text { irregular } 20-30 \mathrm{~mm} \text { calcrete (?) nodules with pitted exteriors, angular limestone } \\
\text { fragments }(20-25 \mathrm{~mm}) \text { and broken shell/bone }\end{array}$ \\
\hline 5 & & 8.5 & No bulk sample \\
\hline 6 & & 8.0 & No bulk sample \\
\hline 7 & $\begin{array}{l}\text { Light Brownish Grey } \\
\text { to Pale Brown: 10YR 6/2-6/3 }\end{array}$ & $8.0-9.0$ & $\begin{array}{l}\text { Very fine to medium silts with minor component of fine sands. < frequency } \\
\text { in } 2-4 \mathrm{~mm} \text { aggregates (rounded nodular) of silts. < frequency in large calcrete } \\
\text { nodules. Frequent clasts of 5-20mm - calcrete or limestone. Some bone }\end{array}$ \\
\hline 8 & Light Brownish Grey: 10YR 6/2 & 8.5 & $\begin{array}{l}\text { Very fine to medium silts with minor component of fine sands (well sorted). } \\
\text { With occasional poorly sorted inclusions and irregular angular clasts of } \\
\text { limestone/calcrete ( } 25-30 \mathrm{~mm}) \text {, occasional large broken bone. Minor flecking of } \\
\text { 0-5mm white carbonate through matrix. Very minor aggregates }\end{array}$ \\
\hline 9 & Light Brownish Grey: 10YR 6/2 & 8.5 & $\begin{array}{l}\text { Very fine to medium silts with minor component of fine sands (well sorted). } \\
\text { Numerous } 2 \text {-4mm subrounded silt aggregates (> with respect to Spit 8). Decrease } \\
\text { in \% of large limestone clasts although occasional and still irregular clasts (angular } \\
\text { to subangular) of limestone } 15-30 \mathrm{~mm} \text {. Carbonate adhering to some smaller bones }\end{array}$ \\
\hline 10 & Light Brownish Grey: 10YR 6/2 & $8.0-9.0$ & $\begin{array}{l}\text { Fine to medium silts, well sorted. Minor fine sands. Minor aggregates (nodular) } \\
2-4 \mathrm{~mm} \text { of silts. < in gravel-sized limestone/calcrete inclusions. Most inclusions } \\
20-40 \mathrm{~mm} \text { are fractured bone }\end{array}$ \\
\hline 11 & & & No bulk sample \\
\hline
\end{tabular}

Light Brownish Grey to

Pale Brown: 10YR 6/2-6/3

Fine to medium slightly gritty silts. > in 1-3mm pellet aggregates. < $1 \mathrm{~mm}$ spotting of carbonate with loose matrix and ped aggregates. $10-15 \mathrm{~mm}$ limestone/calcrete clasts (subrounded to subangular). Bone occasional only

No bulk sample

No bulk sample

Moderately sorted fine sandy silts. Well developed aggregates (1-3mm, mostly subrounded) of sandy silts. Carbonate flecking (white) $<1 \mathrm{~mm}$ throughout both matrix and aggregates. Infrequent irregular 2-3mm inclusions of reddish - yellow colour (5YR 6/6) - possibly burnt clays/soil peds/Fe-rich

Moderately sorted fine sandy medium to fine silts with frequent subrounded to subangular clasts of broken limestone/bone 10-20mm. Numerous aggregates of silty sands/sandy silts in 1-3mm range. Also minor fractured bone typically $<10 \mathrm{~mm}$. NB: Infrequent particles of Fe-rich nodules/aggregates continue from previous sample (typically $1-2 \mathrm{~mm}$, case hardened, with dusty red-brown silty-clay (?) interiors

No bulk sample

Moderately sorted fine sandy medium silts and coarse $(1-5 \mathrm{~mm})$ sandy silt aggregates. Some aggregates $5-15 \mathrm{~mm}$ - deposit better aggregated. Comminuted carbonate $(1-2 \mathrm{~mm})$ in loose matrix and within aggregates. Occasional large (10-15mm) subrounded limestone clasts/calcrete clasts and broken bone (bone has sediment cemented to surface). Dusty red-brown clay-silt pellets $1-3 \mathrm{~mm}$ continue 


\section{Appendix 9.1: continued}

\begin{tabular}{|c|c|c|c|}
\hline SPIT & MUNSELL COLOUR & $\mathrm{pH}$ & DESCRIPTION \\
\hline 19 & Greyish Brown to Brown: 10YR 5/2-5/3 & $8.0-9.0$ & $\begin{array}{l}\text { Moderately sorted fine sandy silts, and 2-5mm aggregates of sandy silts with } \\
\text { carbonate bone inclusions. Sediment adheres to broken mammal bone and is } \\
\text { within the long bone shafts. Occasional larger 5-12mm fragments irregular } \\
\text { partially cemented. Aggregates of charcoal/sandy silts around nucleii of bone }\end{array}$ \\
\hline 20 & Brown: 10 Y $5 / 3$ & $8.0-9.0$ & $\begin{array}{l}\text { Moderately sorted fine to sandy silts. Aggregation increased with sizes } 0-5 \mathrm{~mm} \\
\text { to } 10 \mathrm{~mm} \text { with amorphous carbonate present in aggregates. Broken bone/shell } \\
\text { predominantly < } 10 \mathrm{~mm} \text {, and breakage in 2-4mm faction very high. Occasional } \\
\text { Fe-rich nodules/aggregates of 2-4mm size }-5 Y \text { Y } 6 / 6-6 / 8 \text { (reddish yellow) }\end{array}$ \\
\hline 21 & Brown: 10YR 5/3 & 8.5 & As for Spit 20 with some occasional larger bone fragments \\
\hline 22 & & $8.0-9.0$ & No bulk sample \\
\hline 23 & & $8.0-9.0$ & No bulk sample \\
\hline 24 & Brown: 10YR 5/3 & $8.0-9.0$ & $\begin{array}{l}\text { Moderately sorted sandy silts and sandy silt aggregates. High development of } \\
\text { aggregation and partial cementation. Most sediment is aggregates } 1-10 \mathrm{~mm} \text { wide } \\
\text { size range. Frequent broken bone with partial mineralization of sediment onto } \\
\text { exterior and infilling of marrow cavity within long bones with wide range of } \\
\text { sediment sizes. Dark specking, possible charcoal 1-3mm? }\end{array}$ \\
\hline 25 & Brown: 7.5 YR 5/3-5/4 & $8.0-9.0$ & $\begin{array}{l}\text { Poorly sorted aggregated sandy slightly gritty silts, possibly with some clay. Stiff } \\
\text { cohesive aggregates with 1-3mm flecking of carbonates within silty matrix. } \\
\text { Numerous broken fine fragments of bone (?) - larger bone appears to act as sites } \\
\text { for matrix. (In situ deposit possibly a 1-2mm subrounded pellet aggregates - } \\
\text { with voids, becoming cemented?) }\end{array}$ \\
\hline 26 & Brown: 7.5 YR 5/3-5/4 & $8.0-9.0$ & $\begin{array}{l}\text { Poorly sorted to very poorly sorted. Stiff slightly sandy, gritty clayey silts with } \\
\text { numerous } 2-6 \mathrm{~mm} \text { limestone grits or flecking throughout. Some } 10-15 \mathrm{~mm} \\
\text { subrounded limestone gravels, occasional broken bone, partially encrusted. } \\
\text { Occasional subrounded fine gravels (10-15mm) (elongate) of } 10 \mathrm{YR} 7 / 6 \text { (yellow) } \\
\text { sandy marls. Majority of sediment is a matrix supported sandy clayey silt with } \\
\text { fine carbonate pellets/ very fine gravels (Cave Earth) }\end{array}$ \\
\hline 27 & & $8.0-9.0$ & No bulk sample \\
\hline 28 & Brown: 7.5 YR 5/3-5/4 & $8.0-9.0$ & $\begin{array}{l}\text { Poorly sorted to very poorly sorted. A stiff slightly sandy clayey silt matrix } \\
\text { supporting subrounded limestone grits/pellets. Again some } 10-20 \mathrm{~mm} 7.5 Y R \\
7 / 6-10 Y R 7 / 6 \text { (reddish yellow - yellow) subrounded marlstone clasts. Also } \\
\text { fragments of irregular travertine and fine carbonate pellets, and } \\
\text { travertine/marls/limestone fine gravels (Cave Earth) }\end{array}$ \\
\hline 29 & & $8.0-9.0$ & No bulk sample \\
\hline 30 & & $8.0-9.0$ & No bulk sample \\
\hline 31 & Dark Yellowish Brown: 10YR 4/4 & $8.0-9.0$ & $\begin{array}{l}\text { Poorly sorted stiff sandy silty clays and clayey silts supporting dispersed limestone } \\
\text { pellets (subrounded) } 1-3 \mathrm{~mm} \text { throughout. Structure, massive. Clasts } 8-15 \mathrm{~mm} \text { of } \\
\text { limestone pitted/weathered on surface. Occasional marlstone and } 2-4 \mathrm{~mm} \text { Fe-rich } \\
\text { siltstone fine pellet casts. No bone or shell fragments }\end{array}$ \\
\hline
\end{tabular}


Appendix 9.2: Liang Lemdubu: Test Pit C, Depths (cm) of Excavation Units (Spits) and Deposit Volumes $\left(\mathrm{m}^{3}\right)$ by Spit

\begin{tabular}{|c|c|c|c|c|c|}
\hline SPIT & NW DEPTH & NE DEPTH & SE DEPTH & SW DEPTH & TOTAL VOLUME \\
\hline 1 & 10 & 6 & 9 & 9 & 5.0 \\
\hline 2 & 5 & 6 & 5 & 3 & 4.0 \\
\hline 3 & 5 & 5 & 5 & 5 & 3.0 \\
\hline 4 & 5 & 6 & 5 & 4.5 & 3.0 \\
\hline 5 & 5 & 5 & 5 & .5 & 3.5 \\
\hline 6 & 5 & 6 & 4 & 4 & 3.0 \\
\hline 7 & 5 & 5 & 6 & 5 & 3.5 \\
\hline 8 & 3 & 3 & 4 & 5 & 3.5 \\
\hline 9 & 5 & 4 & 6 & 4 & 4.0 \\
\hline 10 & 7 & 5 & 6 & 6 & 4.0 \\
\hline 11 & 9 & 6 & 4 & 6 & 4.0 \\
\hline 12 & 4 & 6 & 5 & 5 & 3.0 \\
\hline 13 & 5 & 5 & 5 & 5 & 3.0 \\
\hline 14 & 5 & 5 & 5 & 5 & 3.5 \\
\hline 15 & 5 & 5 & 5 & 5 & 3.0 \\
\hline 16 & 5 & 5 & 5 & 5 & 3.0 \\
\hline 17 & 5 & 5 & 5 & 5 & 3.0 \\
\hline 18 & 4 & 5 & 5 & 6 & 3.0 \\
\hline 19 & 6 & 2 & 5 & 4 & 3.0 \\
\hline 20 & 3 & 5 & 5 & 5 & 3.0 \\
\hline 21 & 7 & 8 & 5 & 5 & 4.2 \\
\hline 22 & 5 & 5 & 5 & 5 & 3.0 \\
\hline 23 & 5 & 5 & 5 & 5 & 4.0 \\
\hline 24 & 4 & 5 & 5 & 3 & 4.0 \\
\hline 25 & 9 & 5 & 5 & 7 & 4.2 \\
\hline 26 & 3 & 5 & 5 & 6 & 4.0 \\
\hline 27 & 4 & 5 & 5 & 4 & 3.5 \\
\hline 28 & 9 & 7 & 6 & 8 & 4.5 \\
\hline 29 & 4 & 5 & 6 & 4 & 4.5 \\
\hline 30 & 3 & 6 & 7 & 5 & 4.0 \\
\hline 31 & 6 & 5 & 3 & 3 & 4.0 \\
\hline
\end{tabular}




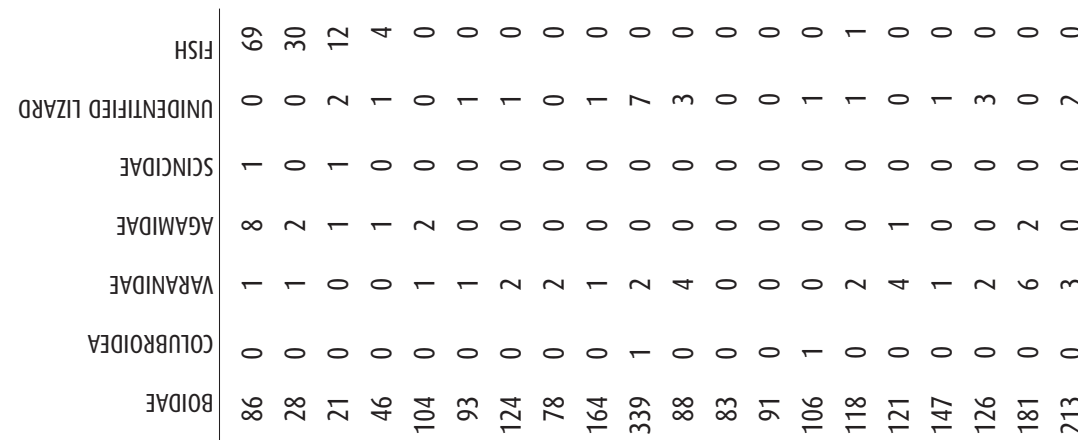

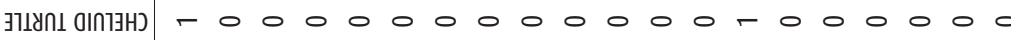
dS SNIYHISHJ - 000000000000000000 -

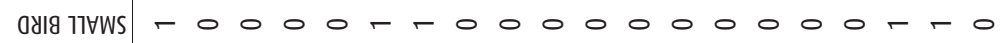
פ0yн - - 00 - 0000000000000 -

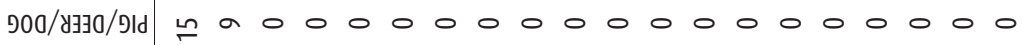
HVINHJ $0-0000000000000000000$

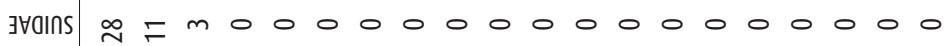

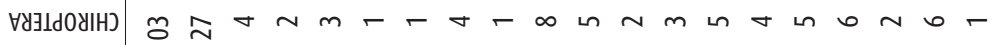

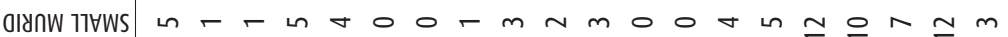

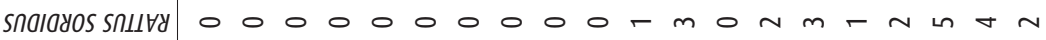

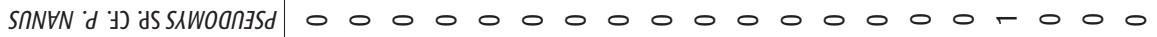
dS SAWONOIOd $00000000000000-0-\ldots+0$ in OSHN SAWOTIWHYHA $00000000000000000-000$

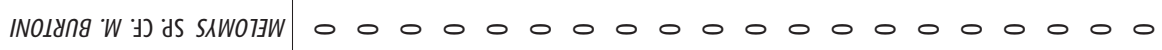
IJASH SAWOYOAHHYHA $00000-0000000000000000$ SกIVTกJHWIONHJ SAWOYח a HIVIYILIYI VIISAOTLIJHO $-0000000-00000000000$

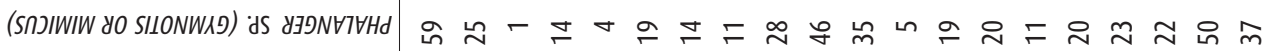

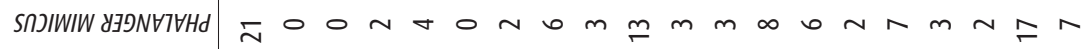

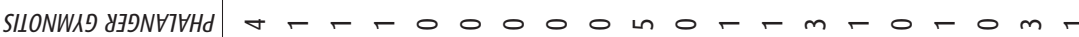

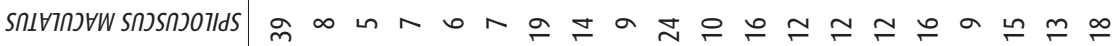

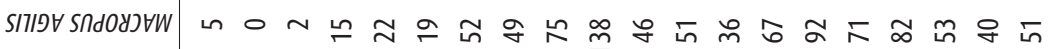

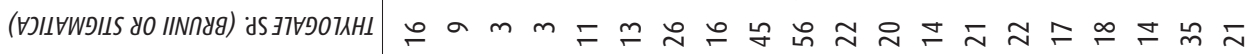

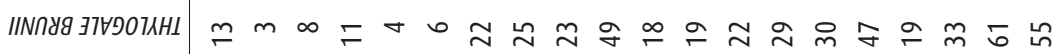

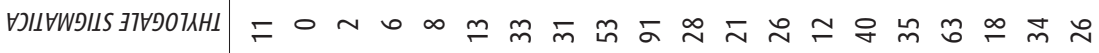
dSSISAOJYOO 00000000000000000000

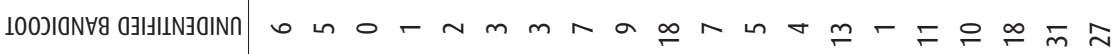

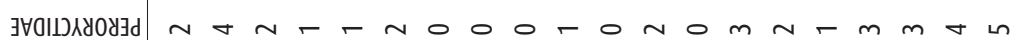
SПупоуวHW NO000SI $-0-m \sim-\sim \sim \sim \sim m m m m m \circ=\bar{\sim}$

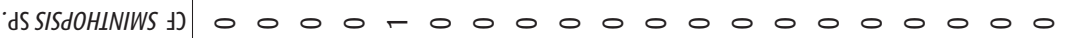
IJJHTHVM SIIJIONW -00000000000000000000

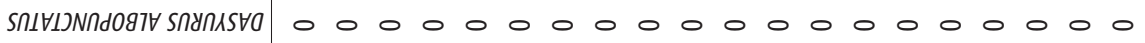

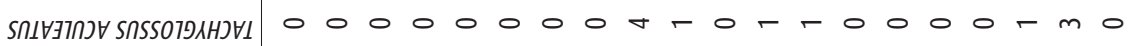

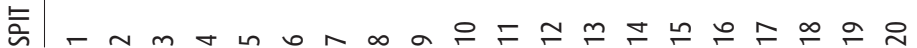




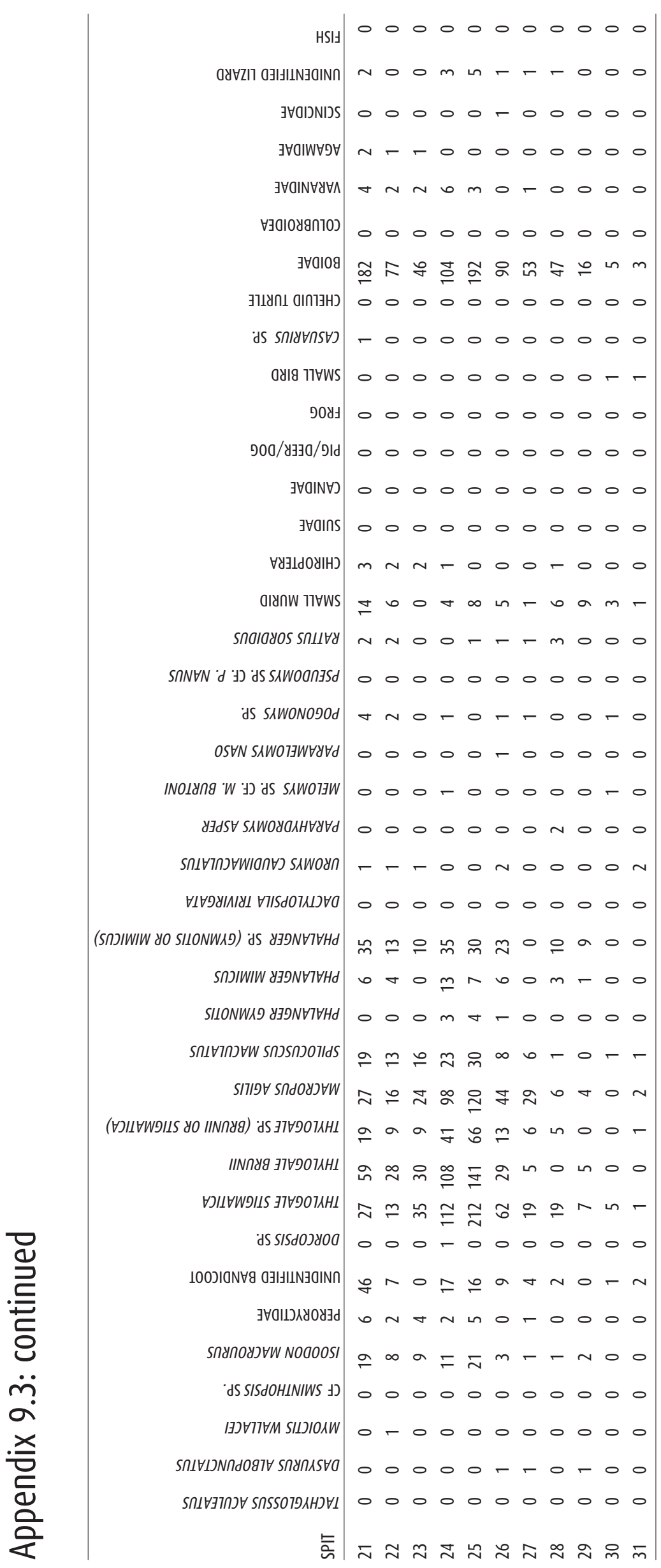




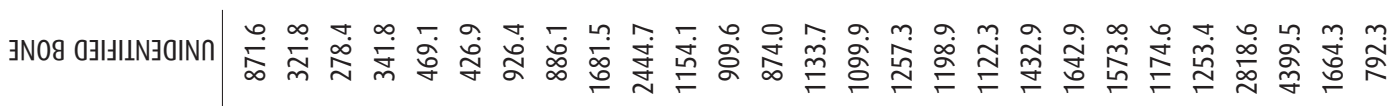

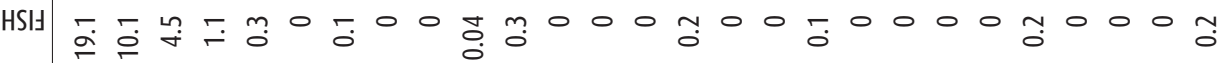

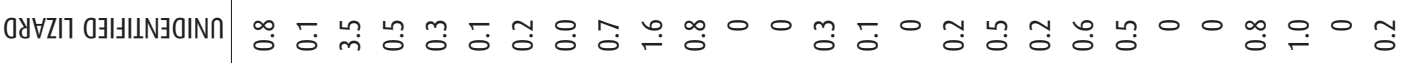

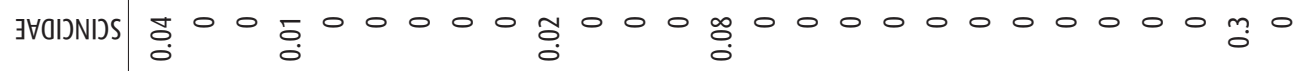

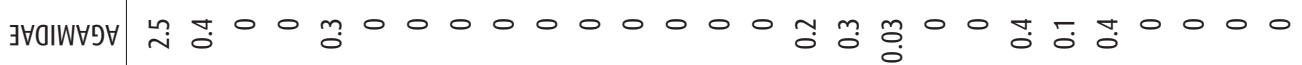

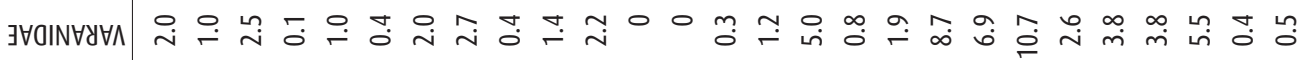

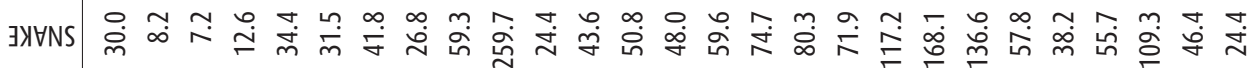

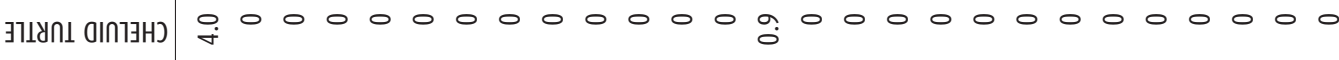

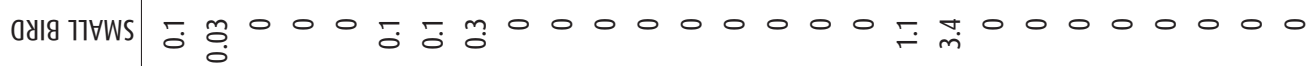

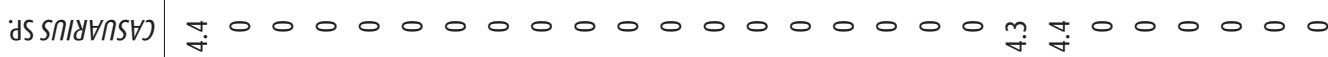
ग0Уन

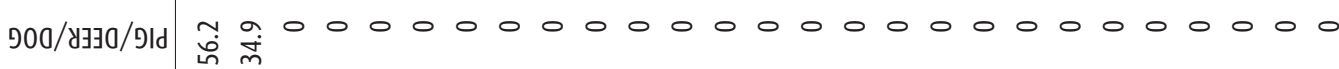
jivinto BVAINHJ $0 ; 0000000000000000000000000$

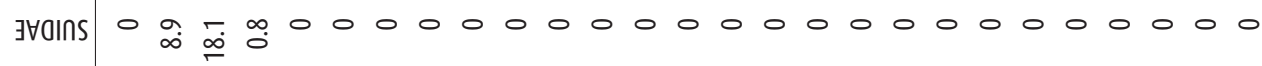

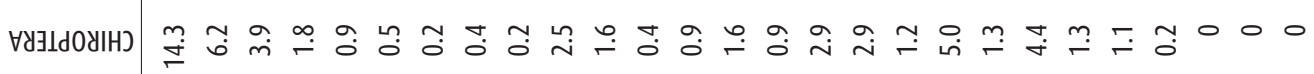

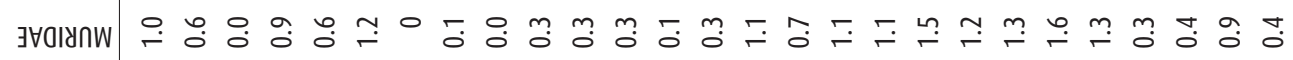

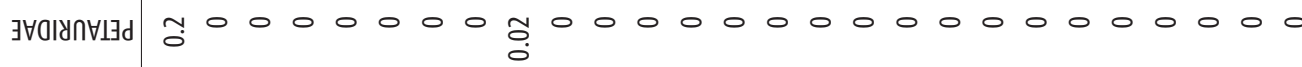

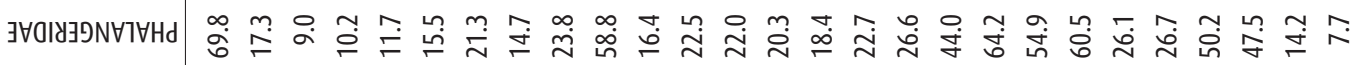

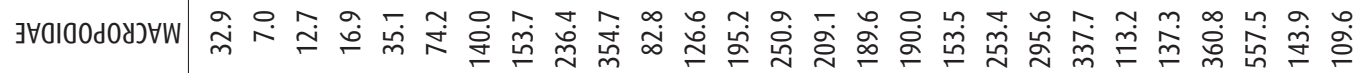

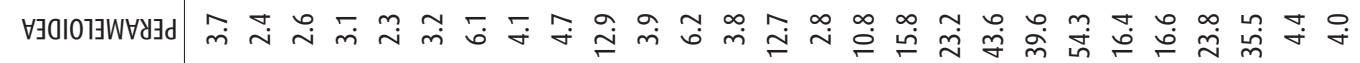
J

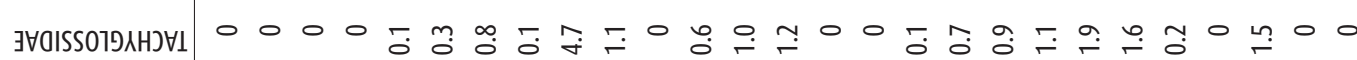

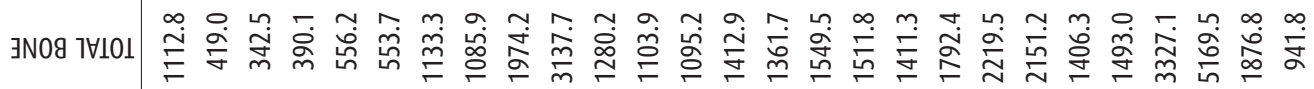

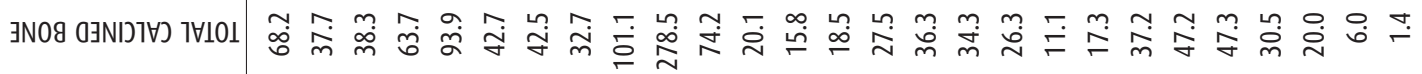

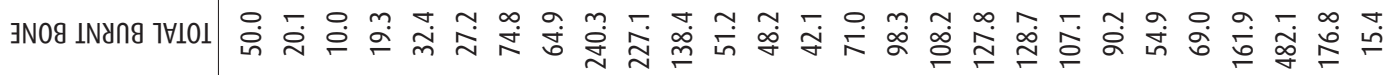

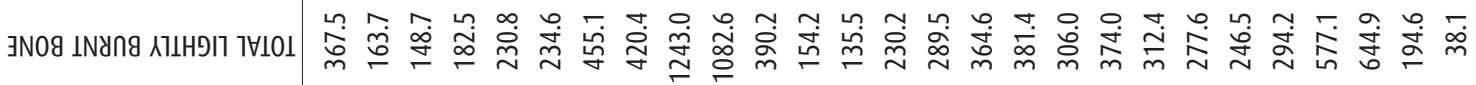

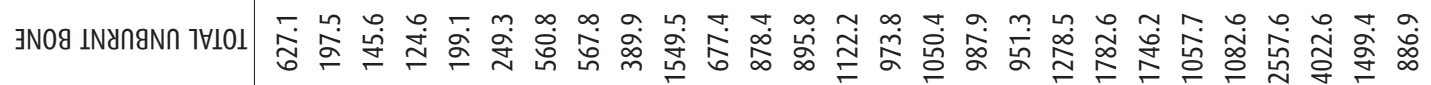
䒺 - n $\forall$ แ 


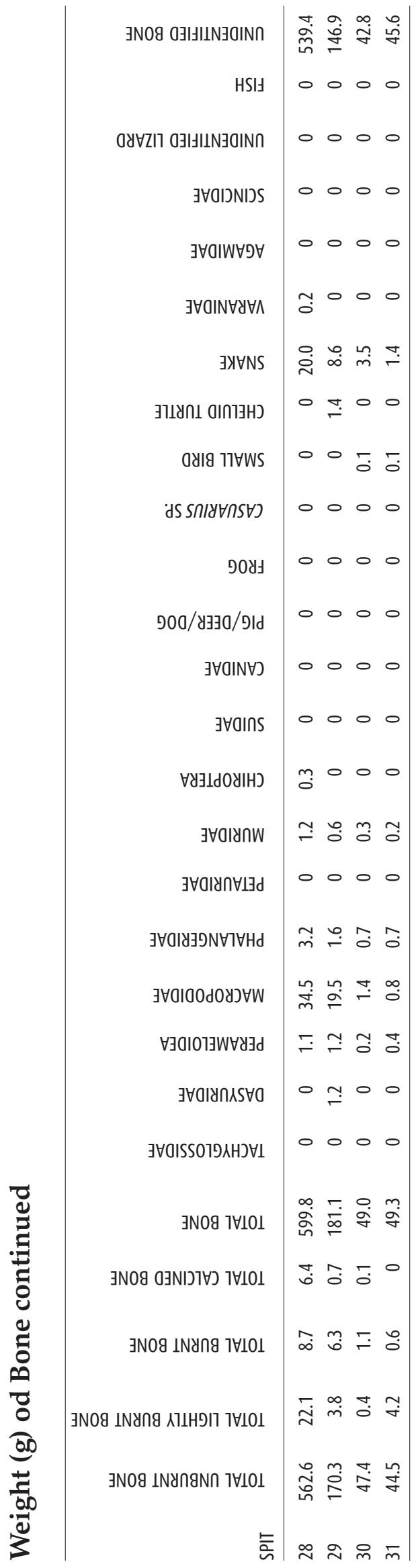

